SANDIA REPORT

SAND97-0049 - UC-700

Unlimited Release

Printed January 1997
RECEIVET

FEB 211997

OSTI

\title{
Information Model for On-Site Inspection System
}

\author{
Olin H. Bray, Sharon Deland
}

Prepared by

Sandia National Laboratories

Altuquerque, New Mexico B7165 and Livermore, Califomia 94550 for the United Sletes Departmenty of Enerty under Conitract DE-ACO4-94-3000 (4)

Approved for pubille release; distinution is unlimiled.

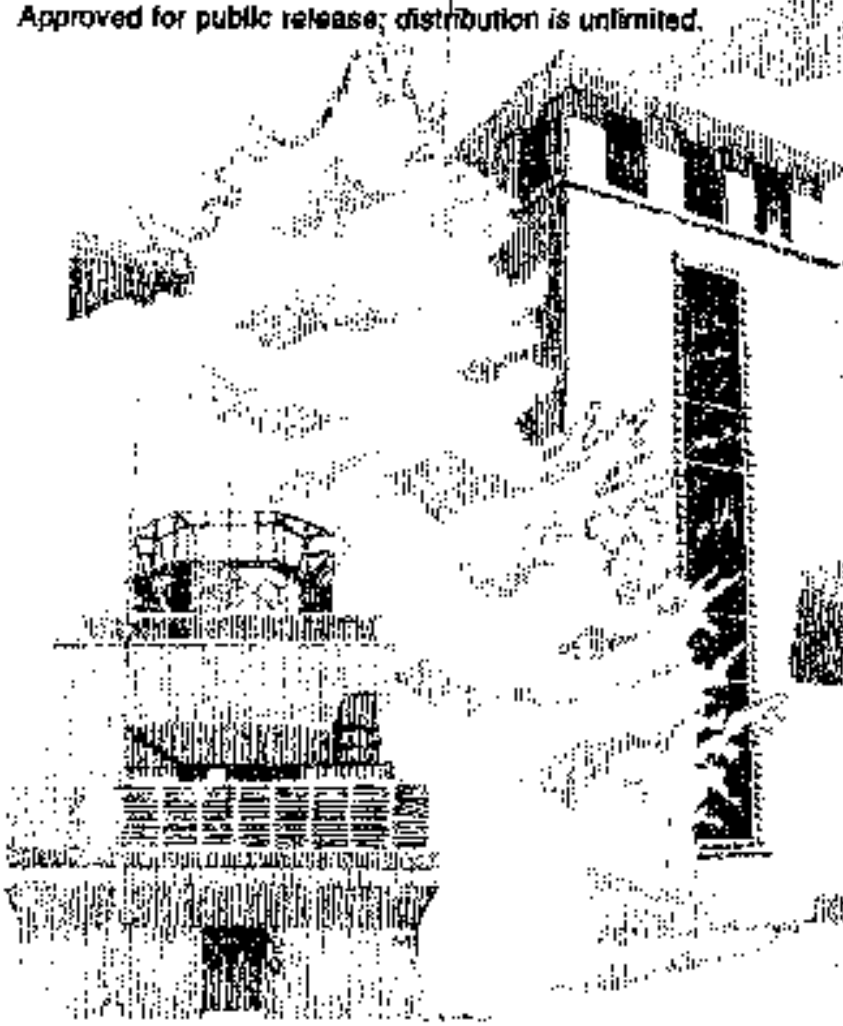

tat

(a)

l,

ing 
Issued by Sandia National Laboratories, operated for the United States Department of Energy by Sandia Coxporation.

NOTICE: This report was prepared as an account of work sponsored by an agency of the United States Government. Neither the United States Government nor any agency thereot, nor any of thisir employees, nor any of their contractors, subcontractors, or their employees, makes any warranty, express or implied, or assumes any legal bability or responsibility for the accuracy, completeness, or usefulnese of any information, apparatus, product, or process disclosed, or represepts that its use would not infringe privately owned rights. Reference hatrin to any specific commercial product, process, or service by trade name, trademark, manufacturer, or otherwise, does not necessarily constitute or imply its endoreement, recommendation, or favoring by the United States Government, any agency thereof, or any of their contractors br subcontractors. The views and opinions expressed herein do not necessarily state or reflect thuee of the United States Government, any agency thereof, or any of their contractors.

Printed in the United Stateg of America. This xepart has been reproduced directly from the best available copy.

Available to DOE and DOE contractors from

Office of Scientific and Technical Information

P.O. Box 62

Oak Ridge, TN 37831

Prices available from (615) 576-8401, FTS 626-8401

Available to the public from

National Technical Information Service

U.S. Department of Commence

6285 Port Royal Rd

Springfield, VA 22161

NIS prios codes

Printed copy. A04

Microtiche copy: A01 
DISCLATMER

Portions of this document may be illegible in electronic image products. Images are produced from the best available original document. 
Date: February 1, 1997

To: Distribution

From: Olin Bray, 4524

Subject: Final Report for FY93 LDRD

Information Integration for Data Fusion

The attached report is one of three reports that resulted from work done under the FY93 LDRD, Information Integration for Data Fusion. Copies are being sent to people who were involved in the project or who might be interested in its results. If you know of other people who would be interested in copies of these reports, please have them contact me or let me know and I will send them a copy.

\section{Purpose of this LDRD:}

Data fusion is the integration and analysis of data from multiple sensors to develop a more accurate understanding of a situation and determine how to respond to it. It can be applied in many application areas, several of which were explored in this LDRD project.

The Information Integration for Dasta Fusion LDRD project had two purposes: (1) to see if a natural language-based information modeling methodology could be used for data fusion problems, and if so, (2) to determine whether this methodology would help identify commonalities across areas and achieve greater synergy. Both of these hypotheses were confirmed. The project found five common objects that are the basis for all of the data fusion areas examined: targets, behaviors, environments, signatures, and sensors. Many of the specific facts related to these objects were common across several models and could easily be reused. In some cases, even the terminology remained the same. In other cases, different areas had their own terminology (e.g., a target in defense, a workpiece or machine tool in manufacturing, or an organ for health care), but the concepts were the same. This commonality is important with the growing use of multisensor data fusion. Data fusion is much more difficult if each type of sensor uses its own objects and models rather than building on a common set. Information model integration at the conceptual level is much easier than at the implementation level.

\section{Report 1:}

The first report, Information Integration for Data Fusion (SAND97-0195) provides a framework for considering data fusion from an information integration perspective, discusses how the synergy generated by this LDRD would have benefited an earlier suscessful project and contains a summary infornation model fron that project, describes a prelininary truce management information model, and explains how information integration can facilitate crosstreaty synergy for various arms control treaties.

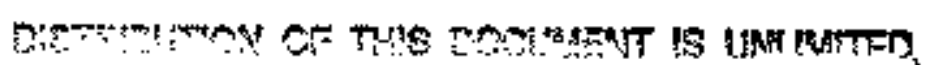

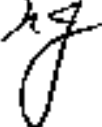




\section{Report 2:}

The second report, Information Model for On-Site Inspection System (SAND97-0049), describes the information model that was jointly developed as part of two LDRDs:

(1) Information Integration for Data Fusion, and (2) Interactive On-Site Inspection System: An Information System to Support Arms Control Inspections. Section 1 describes the purpose and scope of the two LDRD projects and reviews the prototype development approach, including the use of a GIS. Saction 2 describes the information modeling methodology. Section 3 provides a conceptual data dictionary for the OSIS (On-Site Inspection System) model, which can be used in conjunction with the detailed information model provided in the Appendix. Section 4 discussions the lessons learned from the modeling and the prototype. Section 5 identifies the next steps - two alternate paths for future development. The long-term purpose of the On-Site Inspection LDRD was to show the benefits of an information system to support a wide range of on-site inspection activities for both offensive and defensive inspections. The database structure and the information system would support inspection activities under nuclear, chemical, biological, and conventional anms conirol treaties. This would allow a common database to be shared for all types of inspections, providing much greater cross-treaty synergy. The details of the prototype are described in another Sandia report (SAND93-2300), Interactive On-Site Inspection System: An Information System to Support Arms Control Inspections.

\section{Report 3:}

The third report, Data Fusion for Adaptive Control in Manufacturing: Impact on Engineering Information Models (SAND97-0048), consists of four parts: Section 1 detines data fusion and explains its impact on manufacturing. Section 2 describes an information system architecture and explains the natural language-based information modeling methodology used by this research project. Section 3 identifies the major design and manufacturing functions, reviews the information models required to support them, and then shows how these models must be extended to support data fusion. Section 4 discusses the future directions of this work.

\section{Outside Exposure:}

This LDRD work also had exposure outside of Sandia. The first report provided the basis for a presentation, Information Modeling Framework for Data Fuston Problems, at the New Mexico DECUS Conference in Albuquerque, NM, in May of 1993. Part of the first report also provided the basis for a panel discussion at the DOE Expo 93 on Intelligence and Special Operations in Oak Ridge, TN. The third report was the basis for a paper, Data Fusion for Adaptive Control in Manufacruring: Impact on Engineering Information Models, for the ASME Engineering Information Management Symposium in San Diego in August 1993, which was reprinted in the ASME joumal Computers in Engineering.

The work that resulted in the second report (Information Model for On-Site Inspection System) was done in conjunction with another LDRD that actually developed a prototype system based on the model, which was subsequently demonstrated to IAEA and other agencies. This system is now being shown at the Cooperative Monitoring Center. 


\title{
Information Model for On-Site Inspection System
}

\author{
Olin H. Bray \\ Strategic Business Development \\ Sharon Deland \\ Advanced Concepts \& Architectures \\ Sandia National Laboratories \\ P.O. Box 5800 \\ Albuquerque, NM 87185-1378
}

\begin{abstract}
This report describes the information model that was jointly developed as part of two FY93 LDRDs: (1) Information Integration for Data Fusion, and (2) Interactive On-Site Inspection System: An Information System to Support Arms Control Inspections. This report describes the purpose and scope of the two LDRD projects and reviews the prototype development approach, including the use of a GIS. Section 2 describes the infornation modeling methodology. Section 3 provides a conceptual data dictionary for the OSIS (On-Site Inspection System) model, which can be used in conjunction with the detailed information model provided in the Appendix. Section 4 discussions the lessons leamed from the modeling and the prototype. Section 5 identifies the next steps - two altecnate paths for future development. The long-term purpose of the On-Site Inspection LDRD was to show the benefits of an information system to support a wide range of on-site inspection activities for both offensive and defensive inspections. The database structure and the information system would
\end{abstract}


support inspection activities under nuclear, chemical, biological, and conventional ams control treaties. This woutd allow a common database to be shared for all types of inspections, providing much greater crosstreaty synergy. The details of the prototype are described in another Santia report (SAND93-2300), Interactive On Site Inspection System: An Information System to Support Arms Control Inspections. The Information Integration for Data Fusion LDRD project had two purposes: (1) to see if a natural language-based information modeling methodology conld be used for data fusion problens, and if so, (2) to determine whether this methodology would help identify commonalities across areas and achieve greater synergy. Both of these hypotheses were confirmed. The project found five common objects that are the basis for all of the data fusion areas examined: targets, behaviors, environments, siglatures, and sensors. Many of the specific facts related to these objects were common across several models and could easily be reused. In some cases, even the terminology remained the same. In other cases, different areas had their own terminology, but the concepts were the same. This commonality is important with the growing use of multisensor data fusion. Data fusion is much more difficult if each type of sensor use its own objects and models rather than building on a common set. Information model integration at the conceptual level is much easier than at the implementation level. Another Sandia report (SAND97-0195), Information Inregration for Data Fusion, provides a more detailed data fusion framework and addresses this commonality more specifically. 


\section{Contents}

Introduction

Purpose and Scope of On-Site Inspection LDRD

Purpose and Scope of Data Fusion LDRD.

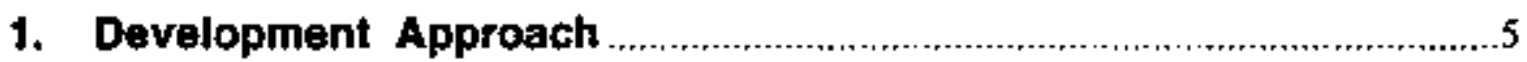

Information Requirements and Model ..........................................................

Geographic Information System ..........................................................7

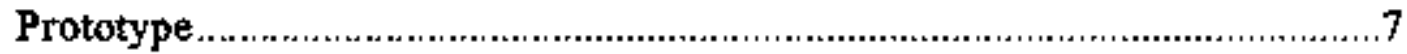

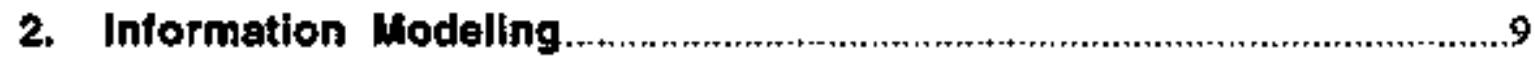

Information Modeling Methodology ...........................................................

Verbal Representation of Information Model ........................................10

Graphical Representation of Information Model ...................................13

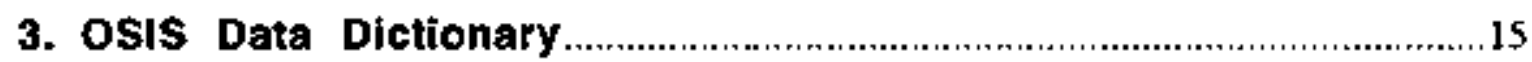

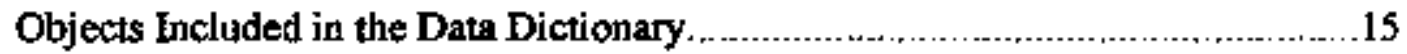

Definitions of the Objects Included in the Data Dictionary .................................17

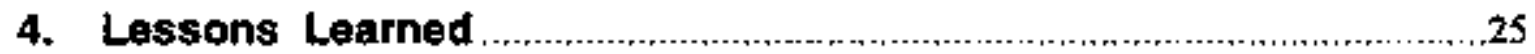

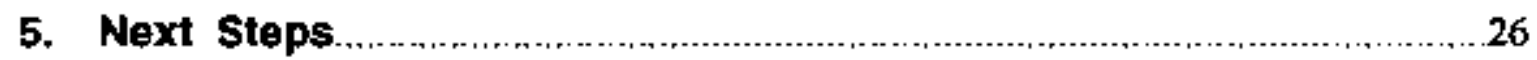

Appendix: Complete On-Site Inspection System Information Model trom CASE Tool (PCMAST).

\section{Figure}

1. Example of graphic representation of information model 
Intentionally Left Blank 


\section{Information Model for On-Site Inspection System}

\section{Introduction}

This report summarizes the joint work done by two LDRDs (LaboratoryDirected Research and Development) in their area of overlap. For more details on each LDRD, see their separate reports (SAND97-0195, Information Integration for Dafa Fusion, and SAND93-2300, Interactive On-Site Inspection System: An Information System to Stpport Arms Control Inspections).

This report explains the purpose of each of the two LDRDs, describes the approach, summarizes the methodology, describes the information model in some detail, summarizes the lessons leamed, and identifies the next steps.

\section{Purpose and Scope of On-site Inspection LDRD}

The work related to this LDRD has both a long-term and a short-term purpose, with the LDRD work focused on the short-term. The long-term purpose was to show the benefits for an information system to suppost a wide range of on-site inspection activities for many arms control treaties. These activities include planning, conducting, and analyzing the results for both defensive and offensive inspections.

- A defensive inspection is one in which your facility is the target of the inspection. In this context, the system should help deternine what is and is not covered by the inspection, where the inspectors go, what they see, and what they can infer from this inspection (and perhaps previous inspections of this or other similar sites).

- An offensive inspection is one in which your inspection team is inspecting someone else's site. In this context, the system should identify legitimate items that can be present at the site, treaty-limited items (and their quantities) that are suspected or found at the site, and evidence to look for to infer the presence of treaty-limited items or behaviors. A sophisticated real time system could even suggest what types of evidence to look for, given the evidence that had already been found, i.e., customizing an inspection while it is occurring. 
The ideal information system would support inspection activities under nuclear, chernical, bjological, and conventional arms control treaties. In most cases, the structure of the database would be the same for the different types of treaties; only the actual data values would be different. This would allow a common database to be shared for all types of inspections, providing much greater cross-treaty synergy. This could allow us to make inferences based on any inspection information, not just data from the current inspection or the current type, e.g., nuclear or chemical.

Obviously, the development of stech as system is far beyond the scope of this LDRD. Therefore, the LDRD work focused on a short-term deliverable: a prototype information system to demonstrate the type of capabilities and functions envisioned for the complete system. The scope of this prototype was constrained so that it could be done within the LDRD time frame; but it would prowide enough substance for members of the arms control and inspection community to evaluate both the demonstration system and the concept and make recommendations for future directions. These demonstrations have generated interest among a number of potential users.

\section{Purpose and Scope of Data Fusion LDRD}

The purpose of this LDRD was to explore the value of information modeling for data fusion. The project investigated the application of natural language-based information modeling for a variety of data fusion areas, including defense, arms control, and manufacturing. It identified a set of objects (targets, behaviors, environments, signatures, and sensors) that are common to all of the examined data fusion areas. It also developed initial high-level information models for several areas and identified their commonality. Information models developed or revisited as part of this LDRD include truce management, Synthetic Aperture Radar (SAR, revisited), ams control, on-site inspections, and adaptive control for manufacturing.

Information modeling uses a natural language, fact-based approach to explicitly model the information requirements for an application area or to integrate a set of application areas. It has been used for requirements definition and for the development of information systems in a variety of areas, but until now was not used in the data fusion area. This LDRD work showed the value of this approach for defining and designing information systems to support data fusion efforts in a wide range of areas.

Although data fusion is a rapidly growing area, there is little synergy and use of common, reusable, and/or tailorable objects and models, especially across different disciplines, e.g., defense and manufacturing. The project had two purposes: (1) to see if a natural language-based information modeling methodology could be used for data fusion problems and if so, (2) to determine whether this methodology would help identify commonalities across areas and achieve greater synergy. 
The project developed or refined preliminary information models for five areas truce management, SAR, On-Site Inspections, arms control synergy, and adaptive control for manufacturing - and looked for commonality across the models. The project found five common objects that are the basis for all of the data fision areas examined. These cornmon objects are targets, behaviors, environments, signatures, and sensors. Many of the specific facts reiated to these objects were common across several models and could easily be reused. In some cases, even the terminology remained the same. In other cases, different areas had their own terminology, but the concepts were the same. For example, the terms "targets" and "signatures" are not common in manufacturing and health care; but many of the facts are the same, so the information motels are easily reusable. 
Intentionally Left Blank 


\section{Development Approach}

There were three major aspects in the development of the On-Site Inspection System (OSIS) prototype:

(1) Development of the information model to support the requirements for various types of inspections.

(2) Learning the capabilities and uses of GIS (Geographic Information Systems)

(3) Development of a working protatype - based on the information model, a traditional DBMS (database management system), and a GIS - for a limited subset of the inspection requirements to see how all of these capabilities fit together.

\section{Information Requirements and Model}

Initially, there were some very general information requirements that were needed to support on-site inspections. The initial flavor of the questions were as follows: Who went on which inspections? What did they see? Where? When? Over time these questions were clarified and more clearly focused, especially once the information model was developed enough to show precisely the type of data that was needed. The following is a sample of the more detailed list of questions:

- Who were the inspectors/escorts on inspection $X$ ?

- What did they see (stops, equjpment, processes)?

- What are the skills and background of inspector X?

- Were any inspectors common to inspections $X, Y$, and $Z$ (same or different treaties)?

- Which OOVs (Objects of Verification) were inspected by inspector $\mathrm{X}$ ?

- Which sites were visited under inspection declaration $\mathbf{X}$ ?

- Under an inspection of OOV unit X, which sites can be inspected?

- Under inspection declaration $\mathrm{X}$, which OOVs and sites should be alerted?

- Given treaty clause X, list anomalies, inspections, OOVs, sites, inspectors. 
- What equipment was seen by inspector $X$ in the last $\mathrm{N}$ months (stops, equipment, processes)?

- List sites and/or OOVs and the number of inspections in the last year.

- Which OOVs have been inspected by teams with skills $X, Y$, and Z? Where were the inspectors on the team employed?

- On inspection $\mathrm{X}$, list all of the stops where there was a mismatch between the skills of the inspectors and the escorts.

- For inspection deciaration $\mathrm{X}$, list all articles published by the inspectors.

- For the sites/OOVs, list all of the processes/equipment related to articles.

- Have any workers at site $\mathrm{X}$ been to a conference with an inspector? Which conference?

The initial information modeling effort was broad enough to include requirements for several different types of treaties, specifically CFE (Conventional Forces in Europe) and $\mathrm{CWC}$ (Chemical Warfare Convention), and for both a defensive and offensive mode. The initial information model covered most of the factors common across many different types of treaties. This version of the information model helped us to precisely understand the problem and its requirements.

Examples of the necessary concepts include treaty, treaty clause, inspection, inspector, escort, site, treaty-timited item, and inspection declaration. At this point, the model also included many of the factors unique to different types of treaties. In some cases, these factors were added to the model without affecting other parts of the existing model, while in other cases the different concepts could be generalized into a common concept that applied across treaties. This information model is one of the few (and the only one we are aware of that takes a broad cross-treaty approach and can capture inspection and site data in a single database for all of the various arms control treaties.

Once the initial information model was developed, a version of it was scoped down to the more limited requirements for the prototype. The prototype was focused on only a defensive inspection under the CWC. This scoping down primarily eliminated concepts. It did not change the structure of the model, so most of what was done with the prototype would also be applicable to the criginal model. (In a few cases, additional real world complexity has not yet been included in either the main or the prototype model. For example, neither model currently addresses the issue that a person - an inspector, an escort, or an observer - can have dual citizenship. However, once this structure is defined, it can be easily added to both information models.) 


\section{Geographic Information System (GIS)}

A GIS is a software application that can relate spatial information (e.g., maps and floor plans) to other information, particularly data stored in relational databases. The GIS used for the PC prototype was ArcCAD, which is really a GIS front end built on dBase, a commercial database management system. The actual production system may be done on a workstation using Arcinfo and ORACLE.

The requirements for, and use of, the GIS integrated very well with the nataral language-based information modeling approach. For example, the information model would specify the types of facts about a machine tool, e.g., its serial number, type, manufacturer, maintenance schedule, size, and location. The size and location would be the data needed by the GIS to either display the machine tool and any data about it or identify which machine tool was selected when someone pointed to a loxation on the screen. The information model for the database did not need to be changed because the database was front-ended by and linked to a GIS.

The actual experience with the GIS was that finding and loading the volume of data required was as difficult, or more difficult, than the actual implementation.

\section{Prototype}

The purpose of the prototype was to show the concept and some of the functionality for an information system to support on-site inspections.

Given the time and resource constraints, the scope of the prototype was limited to support planning for a defensive inspection under the CWC. Therefore, a subset of the broader information model and database design was used for the prototype. Also the prototype was implemented on a different hardware and software platform than would be used for a more complete production system.

Currently, a prototype OSIS has been implemented on a PC laptop using information from Sandia's Tech Area 1 and Buildings 805 and 890 . 
Intentionally Left B]ank 


\section{Information Modeling}

This section briefly describes the information modeling methodology, a natural language-based, fact-based method called NIAM (Njjssen Information Analysis Methodology). This report describes only the main parts of the methodology and how it is used.

\section{Information Modeling Methodology}

This section provides an introduction to the concepts used in natural languagebased information modeling. The information model can be represented in either of two ways - verbally or graphically.

- The verbal representation can be read, critiqued, and corrected by anyone who knows the subject matter, with virtually no explanation of the methodology.

- The graphical representation shows the relationships among the entity types more clearly and concisely, but it does require a few minutes of explanation to be understood. After reading this section, a person should be able to read and understand, although not construct, most of a graphical representation of an information model.

\section{Concepts Covered in this Section:}

- sentence

- elementary sentence

- fact

fact type

fact instance

- entity

entity type

entity instance

- label type

- role/verb

- constraints

total

uniqueness 


\section{Verbal Representation of Information Model}

A sentence is simply a natural language statement by a user describing some aspect of the problem area. It may be simple, describing a specific example or instance "Part X weighs 10 pounds," - or complex - "Part X, which was designed by John Smith last year, now sells for $\$ 100$ and comes in red, green, and blue."

Any complex sentence can be decomposed into elementary sentences: "Part X was designed by John Smith." "Part X was designed in 1994." "Part X in 1995 sells for $\$ 100$." Note that in this case, an elementary sentence is not binary: "Part X in 1995" does not provide the price. "Part X sells for $\$ 100$ " does not specify when, but the price may change over time. The other binary altemative - "1995 sells for $\$ 100$ " - has even more problems. The above sentences were ail examples of specific instances, but they could equally wetl have been done in terms of types: "A part is designed by an engineer." "A part sells for a price in a year." "A part has a color."

The initial problem statement from the user is often a narrative consisting of simple and complex sentences referring to both types and instances. The information modeling methodology provides a way to decompose the problen statement into elementary sentences and formally modet them to unambiguously identify all of the relationships and constraints in a way that the user can review them to verify or correct them.

The user describes the problen in nafural language sentences: sone are already elementary sentences while others are complex sentences. The complex sentences are decomposed into the corresponding elementary sentences. Many elementary sentences are binary, but they do not have to be. The key criterion is that an elementary sentence cannot be decomposed into more basic sentences without losing information, as shown in the previous part, date, and price example.

A strictured sentence, sometimes called a fact, has a very specific form. It consists of two entity types (such as person, part, or department) that are related by a role, usually a verb phrase (such as designs, works in, or is responsible for). Examples of fact types include the following:

- A person designs a part.

- A person works in a department.

- A department employs a person (the inverse of the previous fact).

For each fact type there can be many fact instanees, such as "Bill designed part 1234," or "Sam works in Engineering." 
To completely capture all of the required information, a deep structure sentence or fact has a specific form. Ir specifies the first entity type, its identifier or label type, several examples or instances of that label type, a verb phrase, and another entity's set of information (i.e., entity type, label type, and label instance). Although label instances are sometimes called examples (in the sense that they are examples of entity types), the information modeling methodology really requires examples of facts or fact instances.

Entity type:

Person

Label type:

SSN

Label instance:

$123-45.6789$

Verb:

works in

Entity type:

Department

Lobel type:

Department name

Label instance:

Engineering

Fact instances or examples are critical because they explicitly define the data constraints, which the DBMS must enforce. Let's explain the constraint types using specific examples for the fact pair: "A person designs a part" and "A part is designed by a person."

The total constraint tells whether or not every entity instance of a specific type must participate in the fact type. Must every person design a part? No, so the first factircle is not total. However, must every part be designed by a person? If we assume the answer is yes, then this fact/role is total. If we know anything about a part instance, we must know the person who designed it. (Database experts will recognize that this is a mandatory attribute for an entity; but the user has remained insulated from that designer view.) 
In an actual modeling session, someone may raise the issue that we buy some parts from suppliers and for those parts the designer is unknown and probably irrelevant. In other words, for some parts, one set of facts apply, while for other parts, a different set of facts may apply, although all parts share a common set of facts. This distinction defines the subtype-supertype relationship. The supertype (part) has a set of facts that are common to all of the subtypes (designed part and purchased part). The subtypes are distinguished from each other by the unique set of facts that apply to each subtype. Al] of the common facts (except the identifier) are removed from the stubtypes and are associated with the supertype.

To determine another important constraint - the uniqueness constraint requires an additional example. Consider the following examples for the fact "a person works in a department."

\section{Person Department}

1. Sam Eng

2. Mary Mfg

3. Bill Eng

4. Sam Finance

5. Joe

6. - Accounting

When shown the previous six examples, the user can quickly determine which ones are good:

- Examples 1 and 2 are good because there is no overlap; they are two independent fact instances.

- Example 3 is good because a department (Eng) can have more than one person in it.

- Example 4 is incorrect, however, because a person (Sam) can only be in one department. This defines a uniqueness constraint, an specific instance of a person can only appear once in this fact type.

- Examples 5 and 6 simply document the totality constraints described above. Example 5 is incorrect because every person must be in a department, i.e., the total constraint. Example 6 simply verifies that departments may be created and other data collected about them before people are actually assigned to them. However, this is only a business rule constraint, not a physical constraint, so another company could decide that they wanted to consider example 6 as incorrect. 
After analyzing these examples, a more precise statement of the facts is possible. These were the initial facts:

- A person works in a department.

- A department employs a person.

Considering the examples, the more precise facts are as follows:

- Every person must work in one department.

- A department may employ one or more people. (Note: The zero people case is implied by the "may" in this example.)

The possible uniqueness constraints are that the object on the left may be unique, the object on the right may be unique, each object may be unique, or the combination may be unique. An example of fact with the combination is "a person is assigned to a project." A person can be assigned to many projects and a project can have many people, but you would not assign Sam to project $\mathrm{X}$ twice.

\section{Graphical Representation of Intormation Model}

For completeness, the rest of this section briefly describes the graphical representation of the information model. In Figure 1, the solid circle represents an object or concept in the real world, such as a person, a department, a part, or a release status. Dashed or dotted circles represent data objects that identify or further describe real objects, such as employee name, social security mumber, or release code. Boxes or rectangles represent the roles played by one object type with respect to another. The two boxes together indicate that two roles are complementary - a person works in a department and a department employs a person. With appropriate naming, facts in graphic model can be read as sentences.

Figure 1 shows several basic facts (in both directions) and their constraints. The facts shown include: "a person is iđentified by a SSN," "a person works in a department," "a person designs a part," "a person is assigned to a project," and "a part has a current release status." (Note: The model must specify "ourtent" release status because a part will have many release statuses over time.) The constraints are also shown. The $\mathrm{V}$ indicates a total constraint and the line over a role indicates uniqueness. Obviously there are additional constraint types and symbols, but this should provide the reader with a general understanding of the graphic model representation. The neutral data model that can be generated from the information model (in either its verbal or its graphical representation) can be represented in any of the traditional data modeling notations. 


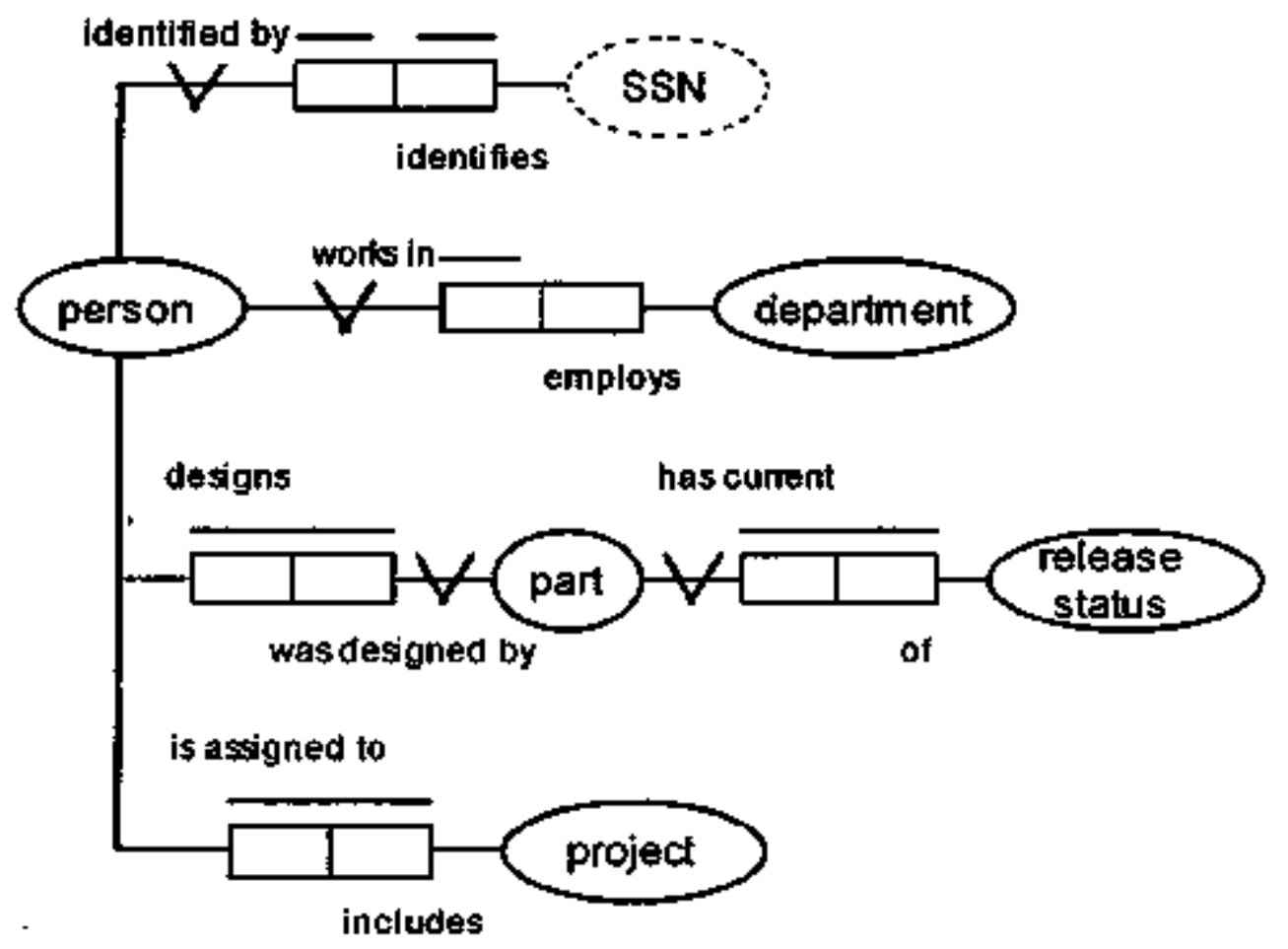

Figure 1. Exarnple of graphic representation of information model 


\section{OSIS Data Dictionary}

This section provides a more general definition and explanation of the major objects in the information model for On-Site Inspections, and in some cases explains why certain modeling dexisions were made.

The Appendix is a copy of the output from one of the CASE tools for the methodology and is a list of the exact facts in the model. A subject matter expert can read and validate or correct these facts with virtually no knowledge of the underlying methodology. This is one of the major benefits of the approach.

The data dictionary should be used in conjunction with the facts specified in the information model for the On-Site Inspection System (see Appendix). The facts are the more precise statement of the information model. This data dictionary provides a more general description of the objects and in some cases sorne of the rationale for them. It is not an attempt to restate the entire information model. However, for people new to either the application area (on-site inspections and treaty verification) or information modeling, reading the data dictionary before or along with the information model can answer some questions that may arise.

This data dictionary includes the 61 major real objects. It does not provide detailed field definitions, as some data dictionaries do.

\section{Objects Included in the Data Dictionary}

- Alliance

- Analysis

- Anomaly

- Building

- Chem-analysis

- City

- Comment

- Company

- Coordinate

- Country

- Country-site

- Date 
- Declaration-limit

- Dacument

- Equip-instance

- Equipment

- Escort

- Escort-observer

- Escort-team

- ESH-requirement (Environmental Safety and Health)

- Function

- Global-position

- Hier-equip-type

- Insp-final-report

- Inspectable-area

- Inspectable-org

- Inspection

- Inspection-declare

- Inspection-tearn

- Inspection-type

- Inspector

- Inspector-observer

- Itinerary

- Linear-dimension

- Location

- Mandate

- Mandate-item

- Organization

- Path-segment

- Person

- Point-of-entry 
- Process

- Region

- Sarnple

- Site

- Site-type

- Special-facility

- Specific-t]-item

- Stop

- Stop-comment

- Technology

- Time

- TL-equipment

- TLnitem (treaty-limited item)

- TL-munitions

- TL-process

- Treaty

- Treaty-clause

- Treaty-limit

- Treaty-site-desc

- Treaty-site-dgrm (treaty site diagram)

\section{Definitions of the Objects Included in the Data Dictionary}

Alliance. An alliance is a group of countries, such as NATO or the Warsaw Pact. An alliance can have many member countries and a country can belong to many altiances. Alliance is important because some treaties, for example CFE, limit items both by country and alliance.

Analysls. See chem-analysis.

Anomaly. An anomaly is a discrepancy between what an inspection team saw and what they expected to see. The expectations may be based on either specific treaty clauses or the initial presentation by the site officials of what is currently at the site. 
These anomalies are documented in the final report of the inspection. (Note: There is an important distinction between an anomaly, which is what an inspection team sees and documents, and a violation, which is a political statement that implies the importance and consequences of the anomaly.)

Bullding. A building is a permanent structure in a site. A building has a location within a site. It also has rooms. A building has a building identifier, which is unique within a site. A building may also have alternate "identifiers," which may not be unique.

Chem-analysis. A chem-analysis is an analysis done on a sample taken during an inspection. The chemical analysis may be done on-site, at a facility located offsite but controlled by the inspected country, or by a facility located at, or controlled by, the inspecting country or organization.

Clty. A city may be the point-of-entry for an inspection team.

Comment. A comment is simply a general descriptive field that can be used in several areas. In some cases, there are specific types of comments, e.g., a Stop Comment, which is a comment made by an inspector at a specific location or stop on an itinerary.

Company. A company is a privately- or government-owned enterprise that provides products or services. A company may be the manufacturer of equipment instances or own the facility or laboratory where a chemical analysis is done. A company has an identifier and a name. It is also located in a country.

Coordinate. A coordinate is the angular component in a giobat position. A coordinate is specified in degrees, minutes, and seconds to whatever level of precision is required (often simply degrees and minutes). A global position has two coordinates, i.e., latitude and longitude. (Note the north-south and east-west codes are included as part of the giobal position, not the cocrdinate.)

Country. A country is any country, which may or may not participate in a treaty. (In a complete model there should be an entry date for when a country became associated or started to participate in a treaty and, correspondingly, a withdrawal date when it ceased to participate.) Countries are identified by a two-character country code and have a country narne. At this time, the model does not include dates for when a country came into existence or when it disappeared - for example, the dissolution of the Soviet Union and the creation of its successor states, some of which are currently nuclear powers.

Country-site. Country sites are special types of sites and were included to support certain CFE requirements. Normally, a site is located within a country and all of the inspections of that site only need to involve that country. However, in some cases there are sites that are located in one country, but are owned and/or operated by another 
country, e.g., U.S. bases in Germany. In this case, both countries must be involved and have certain responsibilities during an inspection and the inspection may be triggered by an interest in either U.S. or German sites.

Date. Date is simply the concept of a date, which is stored in one form, but which may be cutput in any number of formats.

Declaration-limit. The declaration limit specifies how many declarations of an intent to inspect that a country must accept under a treaty during a period of time (usually a year). For example, a treaty may obligate a country to accept five declarations during a year. Note that a declaration is not the same thing as an inspection since several inspections can be included under a single declaration. However, there is a time limit for how long an inspection team can stay in a country under a declaration.

Document. A document is a generic term for any set of information in either hardcopy or electronic form (although not a database). A document is identified by a document identifier (doc-id) and a version. Examples of documents include treaty-site diagrams and descriptions.

Equip-instance. An equipment instance is a piece of equipment, such as a machine tool. It is identiffed by a serial number, is of a type (hier-equip-type), and is in a location. During a defensive inspection, you may want to know what equipment the inspectors saw. During an offensive inspection, you may want to plan your inspection to make sure you check certain pieces of equipment.

Equipment. See Equip-instance and Hier-equip-type.

Escort. An escort is a subtype of person, so all of the facts relating to a person also relate to an escort. An escort usually works at or for the site being inspected or the OSIA (On-Site Inspection Agency). An escort may be assigned to an inspector or to a specific area and will deal with any inspector who comes through the area. Escorts have specific duties and responsibilities, some of which are specified by the treaty under which the inspection is being conducted.

Escort-observer. An escort observer is a "friendiy" observer who may be allowed to accompany the inspection, but who has no treaty-specified rights or responsibilities.

Escort-team. An escort team is the collection of all of the escorts for a specific inspection at a specific site. An escort team may have a permanent existence, but ustally it is simply the collection of individual escorts pulled together for a specific inspection.

ESH-requirement. Environment, Safety, and Health Requirements may relate to locations and/or processes. Since both locations and processes are included in the information model, their ES\&H requirements must also be included. All personnel (e.g., 
inspectors and escorts) must teceive the appropriate training and conform to the ES\&H requirements during the inspection.

Function. The high-level function is performed at a site that may perform more than one function. Currently, this concept is fuzzy, but examples might be manufacturing, precision machining, enrichment, or genetic research. If refined, it could be a useful discriminator - "list all of the sites that can to function X"

Global-position. Global position speciffes the exact position of a point, which may be a site or building reference point, Global position may be determined by a GPS reading. Global position includes latitude, longitude, and elevation. Latitude and longitade are specified by a coordinate (angle) and a code (i.e., north-south or east-west).

Hier-equip-type. This object specifies equjpment type. The concept of a hierarchy was included because there may be a general structure of equipment types. For example, $\mathbf{a}$ welding machine is more general than a laser welding machine. There is a similar structure for manufacturing processes.

Insp-final-report. At the end of an inspection, a final report is prepared, ustally jointly by the inspection team and the site officials. This report is a document. It specifies any anomalies found, their resolution if any, and any other information the particjpants wish to include.

Inspectable-area. An inspectable area is that part of a site inspectable under a certain treaty. For example, part of Sandia may be inspectable under the NPT, while other parts may be inspectable under the CWC. Other parts, such as common areas, may not be formally inspectable, but can be walked through and observed.

Inspectable-org. Inspectable organization is a concept from the CFE treaty. A military unit or organization may be inspectable under some treaties to ensure that its equipment conforms to treaty specifications. However, the unit may be located at many sites. In this case, what is inspectable is the organization itself and the inspectors can go to as many sites as are necessary. This is in contrast to the usual approach where a site is what is being inspected, and if the inspectors go to additional sites they count as additional inspections.

Inspectlon. An inspection occurs when an inspection team goes to a site and examines it for compliance with the terms and conditions specified by the treaty under which the inspection is performed. (Note: Under some treaties, such as the CWC, only sites are inspected; but under other treaties, such as CFE, sites or units may be inspected. In the latter case, a new term - Object of Verification (OOV) - is often used, where an OOV can be either a site or a unit) Inspections must be authorized under a treaty and are announced ahead of time by an inspection declaration. The treaty specifies the nules under which the inspection is carried out, The result of the inspection is a final report, which 
may identify one or more anomalies. Violations represent a political judgement and decision about the seriousness of the anomalies. This judgement is not made at the site by the inspection team, which only deats with anomalies.

Inspection-declare. An inspection-declare is a declaration of the intent to inspect.

Inspection-teem. An inspection team is the collection of all of the inspectors for a specific inspection declaration, which may cover inspections at one or more specific sites. An inspection team may have a permanent existence, but usually it is simply the collection of individual inspectors pulled together for a specific declaration or set of inspections.

Inspectlon-type. Treaties authorize various types of inspections. Examples include baseline inspections to establish a starting point, shutdown inspections when a facility is being permanent closed, and routine inspections.

Inspector. An inspector is a stbtype of person, so all of the facts relating to a person also relate to an inspector. An inspector is usually either a citizen of the inspecting country or an employee of a monitoring organization such as the International Atomic Energy Agency (IAEA). Inspectors have specific duties, rights, and responsibilities, whitch are specified by the treaty under which the inspection is being conducted.

Inspector-observer. An inspector observer is a special "unofficial member of the inspection team, who may be allowed to accompany the inspection, but who has no specific, treaty-specified rights or responsibilities."

Itinerary. Inspectors can ask to see various locations, equipment, and/or processes at a site. An itinerary is a subset of an inspection where one or more inspectors and their escorts make several stops at a site to inspect requested items. An inspection may consists of one itinerary (if all of the inspectors stay together and see the same things) or it may consist of many itineraries done sequentially or in parallel (where different inspectors examine different parts of the site).

Linear-dimension. Linear dimension is simply the common unit (measured in a specified metric or English unit) for measuring distances such as length, width, height, or elevation.

Location. A location is a precise point within a site, for example a room within a building within a site.

Mandate. The mandate specifies the purpose of the inspection, i.e., what the site is suspected of doing. In this usage, a mandate only applies to challenge inspections 
where there is suspected treaty violations or anomalies. Mandates do not apply to routine inspections.

Mandate-item. A mandate may indicate several suspected violations, for example the possession and manufacture of several precursor chemicals. The mandate item is a single item or suspected violation within the overall mandate.

Organization. An organization is either a company or a subunit within a company.

Path-segment. A path segment is part of the itinerary for an inspection. The inspection itinerary includes a number of stops and a path segment is the segment between any two of those stops.

Person. Person is a supertype that contains the basic information (facts) common for every person. It includes facts such as identifier, aame, birth date, and citizenship. Additional information is captured in subtypes based on the one or more roles the person plays. Examples of these subtypes include inspectors, escorts, escortobservers, and inspector-observers.

Point-of-entry. A point-of-entry is the city through which an inspection team must enter a country. Points-of-entry for each country are specified in the treaty. Pointsof entry may be related to specific sites to be inspected. For example, New York may be the point-of-entry for Oak Ridge, and San Francisco the point-of-entry for Sandia.

Process. A process is an activity that may be performed at a location.

Region. A region is simply a geographic area defined in some way by a treaty. It may be a list of countries, parts of countries, or a set of boundaries from specific points of landmarks.

Sample. A sample, e.g., a chemical sample, may be taken at any point during the inspection for further analysis to identify suspected clandestine activity or to confirm that such activity is not occurring.

Site. A site is normally the largest area subject to an inspection under a specific treaty. Inspecting more than one site is normally considered multiple inspections. The main exception is that under CFE, a single inspection of a military unit includes all of the sites at which that unit is based.

Site-type. At one level, site type specifies the type of activity at the site, e.g., nuclear or chemical. At arother level it may include the status of the site, e.g., shut down processing for a former chemical site.

Special-facility. Any special facilities that need to be called out for the site. 
Specific-ti-Item. A specific treaty-linited item is simply a more precise or more detailed identification of a type of item. For example, a TL-item may be fighters, whereas a Specific-t-item may be F-15E or F-18. Each type of TL-iten (e.g., fighters, tanks, APCs, or attack helicopters) can have a list of specific treaty-limited items of that type.

Stop. During the inspection, the inspectors may stop at any point to ask questions, examine something in more detail, or request a sample. The stop provides information about this activity.

Stop-comment. Any relevant comment an inspector made during a stop.

Technology. Technology identifies the technology involved in either a type of equipment or a process found at a site.

Time. A timestamp used as part of the identifier for a stop.

TL-equipment. See TL-itern.

TL-item. A Treaty-Linited Item (TL-item) is any item in any way limited by the terms of a treaty. These limits may involve the development, production, deployment, use, retirement, decommissioning, and/or disposal of an item. Item is used in a generic sense and may include any of three subtypes of items - equipment, processes, or munitions. The TL-items, their limits, and inspection procedures for verifying compliance are all specified in one or more treaty clauses.

TL-munitions. See TL-item.

TL-process. See TL-item.

Treaty. A treaty is an international agreement signed and ratified by a group of participating countries that specifies a set of nules of behavior in certain areas and possibly sanctions for noncompliance. For example, with arms control treaties, there are precise definitions of what is being controlled, how it is to be controlled, how it may be disposed of, and how to conduct inspections to verify a country's compliance with the treaty terns. All of these points are defined and described in detail in specific treaty clauses, which are uniquely identified.

Treaty-clause. See Treaty.

Treaty-limit. See TL-item (Treaty-Limited Item).

Treaty-site-desc. The treaty-site-description is a document that describes the general functions, activities, and equipment of the entire site, part of which may not be covered under the specific treaty. It provides a more detailed description for functions 
and activities of the site covered by the treaty. A site may have many of these descriptions because they are specific to each treaty under which the site is covered.

Treaty-site-dgrm. The treaty-site-diagram is a document or map that shows the general layout (e.g., builting outlines, roads, and fences) of the entire site, part of which may not be covered under the specific treaty. It provides a more detailed layout for that part of the site covered by the treaty. A site may have many of these diagrams because they are specific to each treaty under which the site is covered. 


\section{Lessons Learned}

Overall the GIS software provided a useful tool for presenting data to help in conducting on-site inspections. However, during the inspection, data collection took time and limited the speed of the inspection process. Other data collection methods, such as video and audio with later entry into the database, would have speeded up the inspection process, but then the data would not have been available until after the inspection. There is also a major hurdle in data collection and processing to prepare a site for an inspection. These pre-inspection activities include collecting and reducing the geographic data and creating, building, and maintaining the necessary databases.

The natural language-based information modeling methodology helped provide a better understanding of the inspection process and its data requirements. It also helped integrate concepts across arms control treaties. There was no difficulty linking the model results within the GIS context. The major limitation was that the GIS used for the prototype was implemented using $d B$ ase, which has certain limitations. These limitations prevented us from using the database schema generated directly from the information modeling tool. However, the information model and the understanding developed during the modeling process provided the implementers with an effective starting point and allowed rapid design of the prototype database.

The OSIS model reused and/or built on a number of the objects (e.g., coordinate, giobal position, and site) from other data fusion information models. This reuse would increase with a more detailed model or with inspections for a different type of treaty. For example, the CFE treaty would probably have included vehicle types, configurations, and images from the information model for a SAR system. 


\section{Next Steps}

This work can continue along at least two different paths: First, the on-site inspection aspect of the work could continue to extend and refine the prototype and/or move in the direction of a more complete information system to support on-site inspections, preferable in a broad multitreaty context for both the defensive and offensive modes, i.e., retum to, extend, and implement the broader initial model. However, ideally this should be done within the context of a real customer who has specific requirements. In fact, demonstrations have been provided to a number of potential customers, who have expressed an interest in the system. Discussions are continuing with these customers.

Another path would take the work more into the data fusion area This approach would extend the information mode! with specific types of targets and behaviors likety to be encorntered in arms control inspection sipuations, the way they would be perceived by various types of sensors that could either be carried in by an inspection team or left at a site permanently for long term monitoting. For more information on this approach, see SAND97-0195, Information Integration for Data Fusion, Section 4, "Data Fusion and Information Modeling Technology for Nonproliferation," which also addresses the use of information modeling technology for cross-treaty and cross-methods synergy. 


\section{Appendix:}

Complete On-Site Inspection System Information Model from CASE Tool (PC/IAST) 
Elenentory Sentence.

A 2-LTR-DONTRY-CCOE is a LABEL TYPE with representotion Aharacter 30.

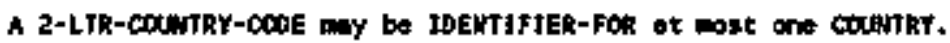

An MLlaHCE is an QeJect.

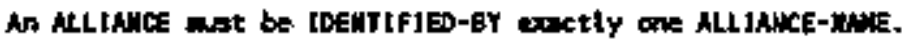

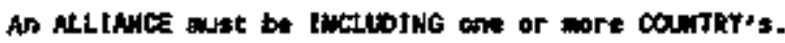

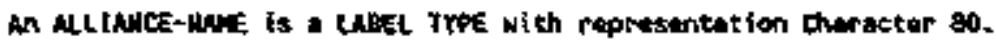
An ALLIANCE-IHUE Ray be JOENTIF1ER-FOR at most one MLLAMCE.

An ABALYSTS is an OOJECT.

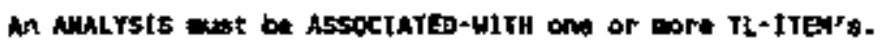

An Nulysts mst be DCAE-AT exactly one LOCATJON.

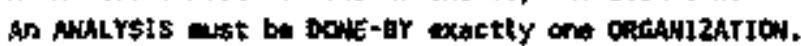

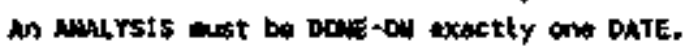

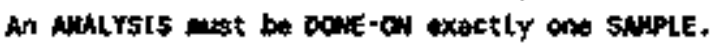

An whalYsts ant be FOR axactly one IUSOECTOA.

An Ald

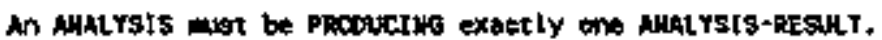

M AlALISIS mist be WITH exactly ore AHALYSI5-TYPE.

Every Atursis

is associated uniquaty with one consination of

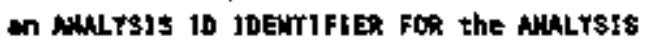

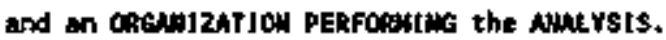

An AraLYS1S-10 is a LABEL TYPE with representation Museric 5.

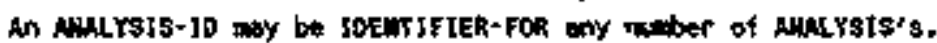

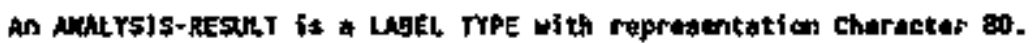

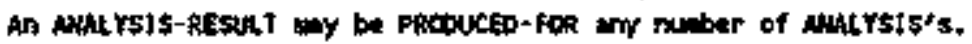

An Mutrsis-TYPE is a LABE2 TPPE with representation Choracter 30.

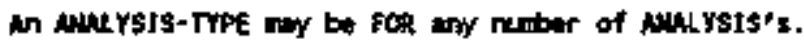


Elementary Sentence.

An Arounur is an 08JECT.

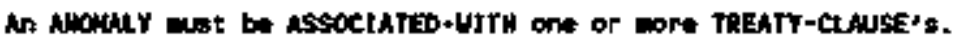

in Alowaly mot be DJSCONERab-BY exectly one Dasow.

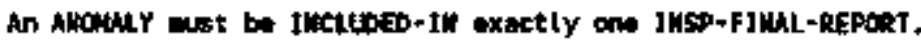

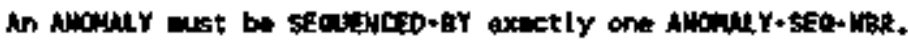

Every Alowily

is associoted uniquely with one expination of

in IUSP ft

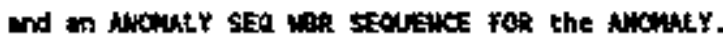

An Awouly-sEo-NGR is a LABEL TYPE with repreantezion Munir ic 5.

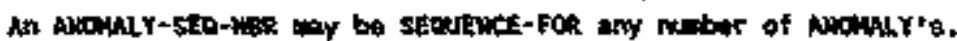

An AlHok Ia a LABEL TYPE with rapresentation Character 40. An Alrtion may be bittek-of any nuber of Doculan's.

A butlpius is an bestect.

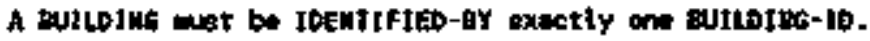

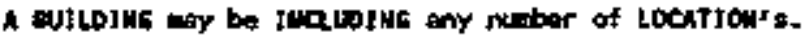

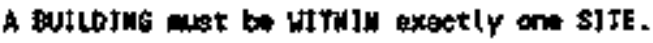

Evary guildikg

is sssociated uniquely wh the acmbination of

- S17E IUCUDJK the ButLing

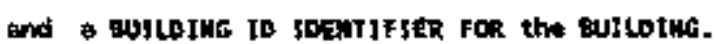

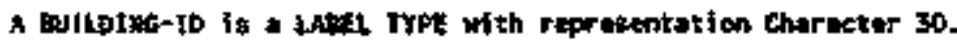

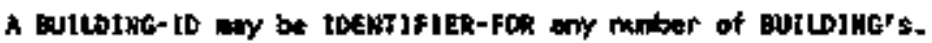

A CITY is an OQject.

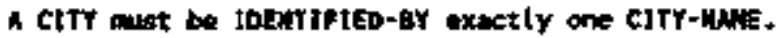

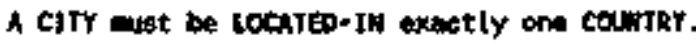

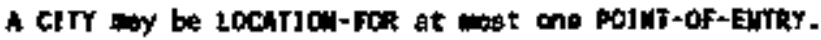

Every clTr

is associteted uniquely with one colbination of

- CITY wat IOfNTIFrar FOR the CITY

and conctRr Locktton for the ciTr. 
Elementary sentenct.

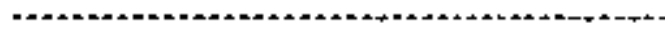

A eltr-unt is a lacel Trpe with represtontotion character 30.

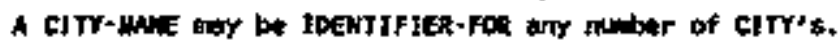

A CHTEY-SITE-JD is a LABEL TYPE with tepresentation choracter 6 .

A CHTRY-SITE-JD Doy be IDEMTIFIER-FOR at nost ane COUNTRY-sITE.

A CONHEks is an OBNECT.

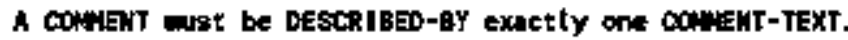

4 CONHEir noy be FOR any muber of STOP-COHEIT's.

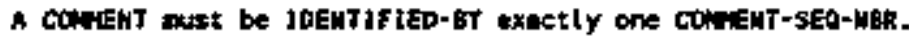

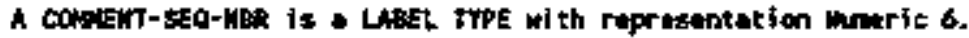

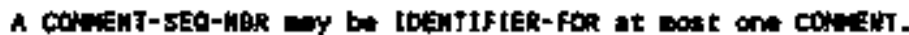

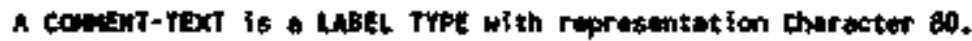

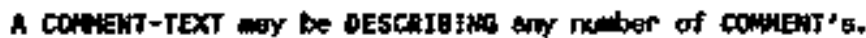

A COMPArY is on OBJECT.

A CONPAir anst be JDENTIfIED-BY exactly one COMPAYY-COOE.

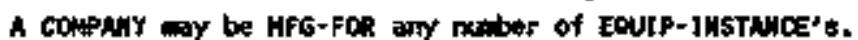

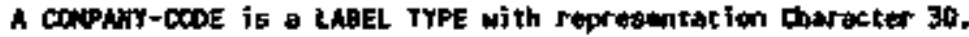

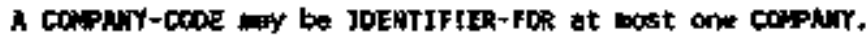

A COCRDIMATE is an DQJECT.

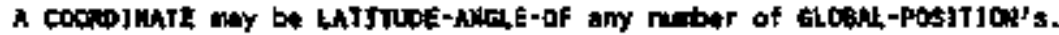

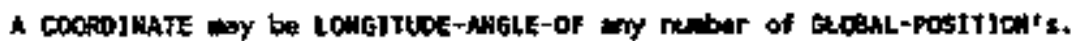

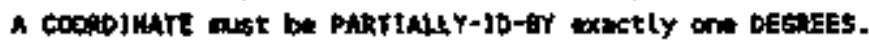

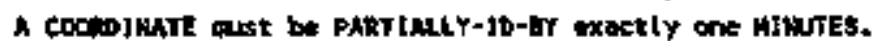

Every tookptikte

Is associated uniquely with ore conbination of

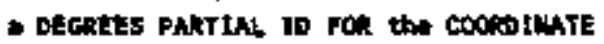

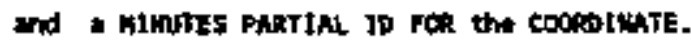


Llementary senternc*

$A$ Country is on OBJECT.

A CWNTRY my be DECLARIWG any nuber of INSPECTJOW-bECLARE's.

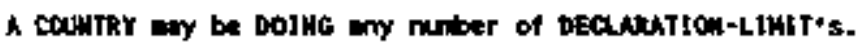

A COANTRY way be OUAL-CITJZEH-FOR any nuber of PERSON's.

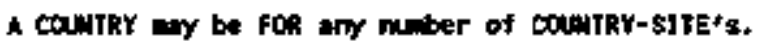

a cawtri my be foR any muber of polut-of-EMTRY's.

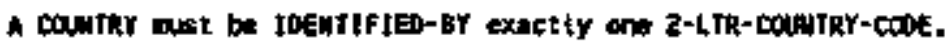

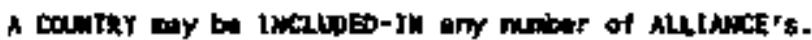

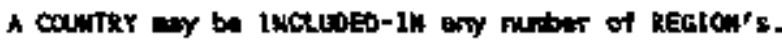

a counter ay be LOCATION-FOR my neter of citr's.

A COUNTRY WO be LOCATIOW-Of ary nuber of TREATY-LIHTT's,

A CONIRY wy be OANER-FOR any neber of TREATY+LIMIJ'B.

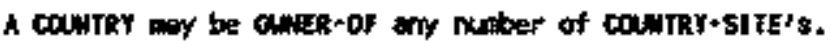

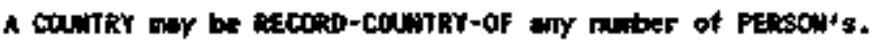

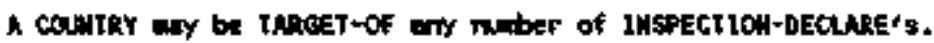

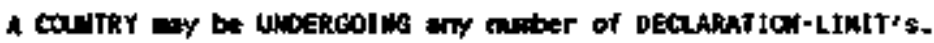

a cantky ast be WiTl exuctly one colmiky-Mure.

A cowizY-WUE is a LABEL THFE with reprosentation character 80.

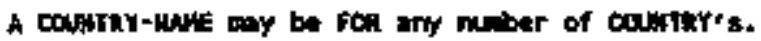

A CONART-SITE is an acect.

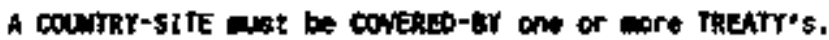

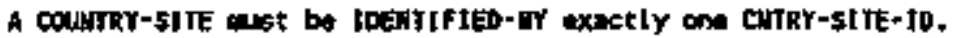

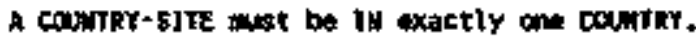

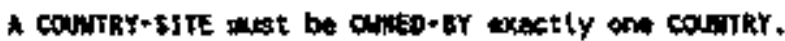

A DATE is in CAJECT.

A DATE WY be DATE+DECLARED+FQ any number of INSPECTION-DECLARE's.

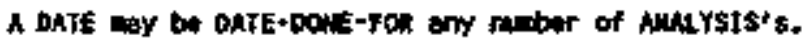

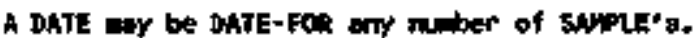

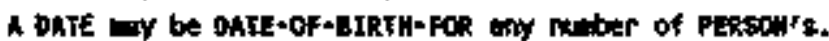

$A$ DATE $M$ be and-DATE-FOR ary nomber of IUSPECTEOW's.

A DATE GSY bE ENTRY-DRTE-FCR anY mubar of JUSPECTION-DECUARE'S.

A DATE GY be of-EXIT-FOR any muber of JUSPECT JOW-DECLARE'S.

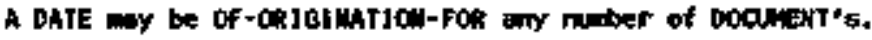

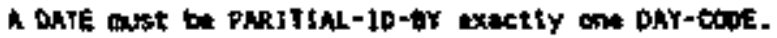

$A$ OATE INEst b PNRTIAL-ID-bY exactly one MOUTH-CODE.

A bNTE ant be PAkT1AL-ID-EY exactly one Yenk-COOE.

A ONTE ay be STARTIMG-bATE-Fit any nuber of LUSPECTLON's.

Every DATE

is assocfinced unfqualy with one comblnation of

a DAY CODE PALTIAL ID FOR the DATE

and a HOWTH LOOE PARTIAL ID FO the DATE

and a YEAR COOE PARTJM tD FOR the DATE. 
El eoentary Sentence.

A DAY-cope is a LABEl TYPE with representotion tharucter $Z$.

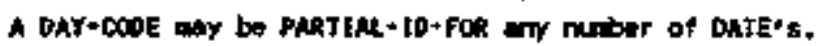

A DECLARATICH+LLHE is en OQVECT.

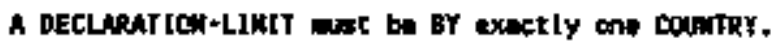

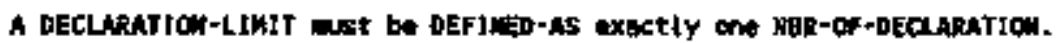

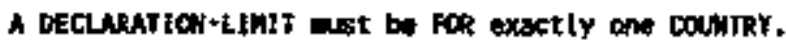

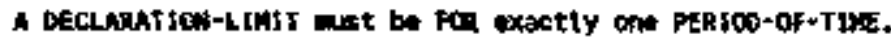

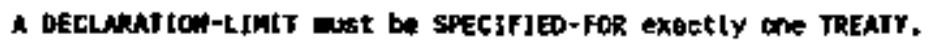

Every DECLARATJa' Ltmit

is associated unigety vith on combination of

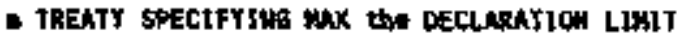

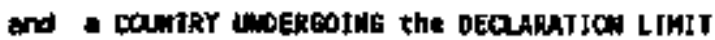

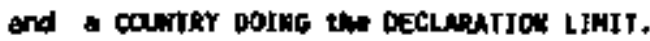

* DEGREFs is a LABE TTPE with representetion humeric 7.

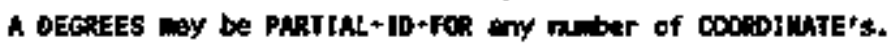

A Doancewt is on QBject.

A OCONEAT mist bo ORI61MATED-ON exoctily one DATE.

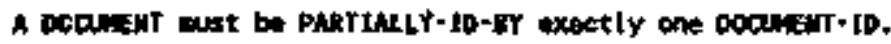

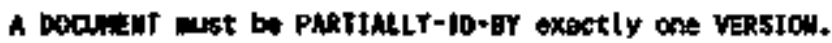

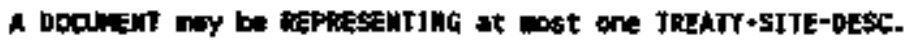

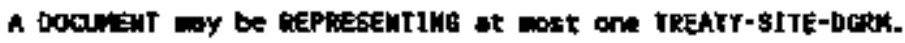

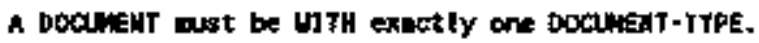

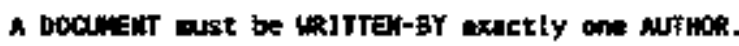

Every Docinakt

is associated unigeiy with on combination of

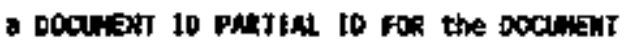

and a Vensjow panjol to rov the podnest.

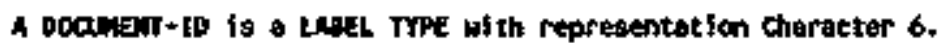
A DOCMENT-ID ay be PARIIAL-ID-fOR any nuber of DOCNan's.

A DOCWEAT-TYPE is a LAEL TYPE with representation Cheracter 5.

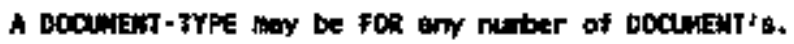


Oote: 5/ $2 / 93$

Model Description in current tenguge.

Paga: 6

Hadel Wane: : OSIst

Version : 2.40:

Etenestoty Sentence.

An EOUIP-IMSTAHCE is in OBJECT.

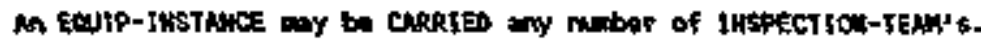

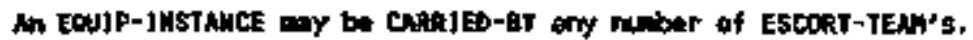

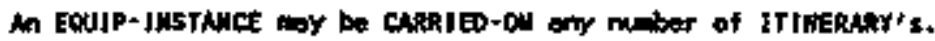

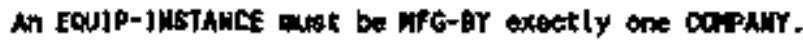

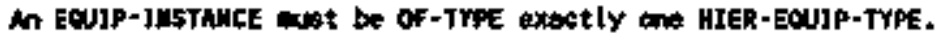

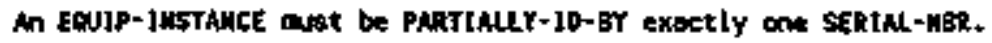

Every EOUIP Insthatce

is associtted wipely with one comingation of

a conparr wFi fon the EOUIP IUSTNMCE

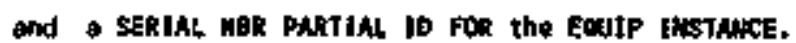

Ah ESCORT is an COJELT.

An ESCORT is alwaya a kind of PERSOW.

An ESCORT way be CHFEF-ESCORT-FOR ony nutber of ESCONY-TENH's.

An ESCORT may be ESCCET-FOR any heber of STOP's.

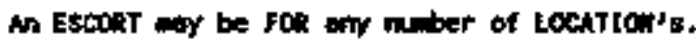

An ESCORT miy be OWERHEARING any muber of STOP-CONENT'A.

in ESCORT mast be PART-Of ore or more ESCORT-TEN's.

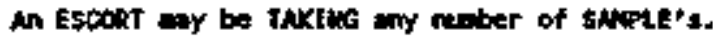

An ESCORT-00SERVER is An GeJEet.

in Escort-geservar is eltyot a kind of PERSCW.

An ESCORT+TEAH fó an OAJECT.

An ESCORT-TEAH moy be CARRYIMG ony muber of EOUIP-JKSTMCE's.

in ESCORl-TEAH must be ESCORTIHG one or more IHSPECTIOW's.

An ESCORT-TEAM must be IDEXTIFIED-BY ExMetlY one ESCORT-TEAH-LO.

in ESCERT-TEAN wat be IHCLDING one or more ESCONT's.

in EsCORT-TEAH mast be IHCLNTHG-A-CHIEF exbetly one ESCORT.

An ESCORT-TEAt-10 is a LeAEL TYPE with representution Character 6. in ESCORT-TEAM-IO woy be IDEKTIFIER-FOR at wat one ESCORT-TEMA.

An ESH-PEQU1REKENT is on OQJECT.

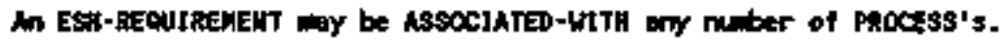

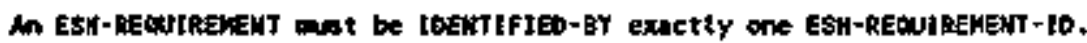

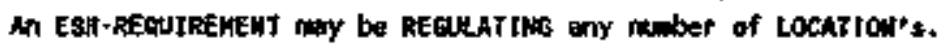


Elenentwy Sentence.

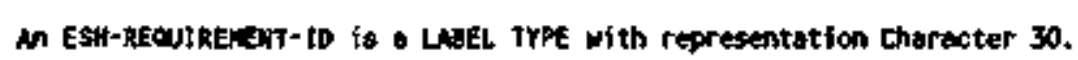

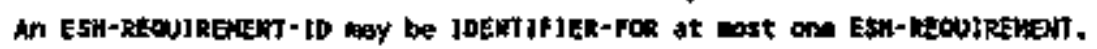

A Functuan is an beject.

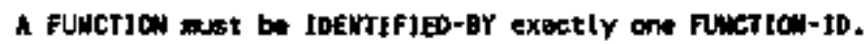

A Function may be PERfokizD-AT amy rumber of SJJE's.

A FUNCT JCA-ID is a LABEL TYPS wh th representation theracter of.

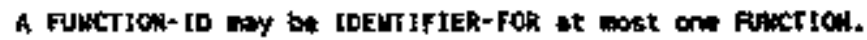

i Gloshl-posttión is an Coject.

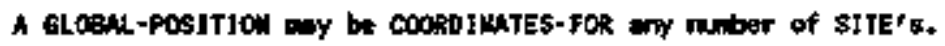

A CLOBAL-POSITICH wast be FOR-LATITIDE exoctly one conojuate.

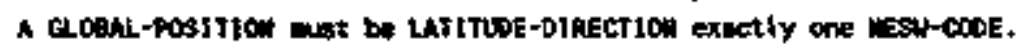

A CLOBAL-POSITtOA wat be LONGtFCOE-DLRECT exactly one MESA-CODE.

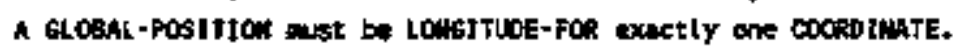

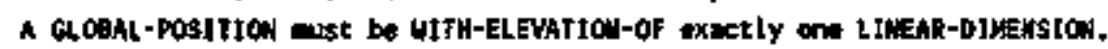
Every thorel posItion

18 assucieted thicuety with on conbination of

a COCRDIMATE LATITDE MITLE OF the GLOML POSITION

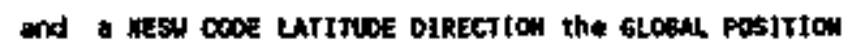

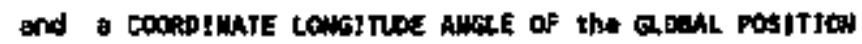

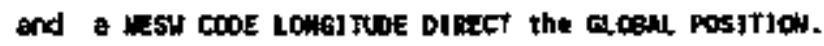

A GIER-EOP-TYPE-DESC is a LUEEL TYPE w1 th representetion Character 80.

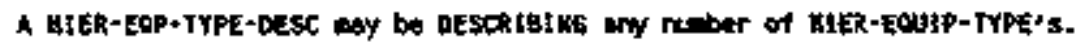

A HER-EOUIP-JYPE is an CAuEtT.

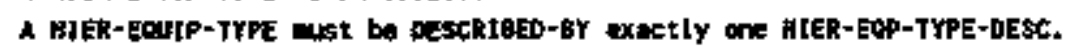

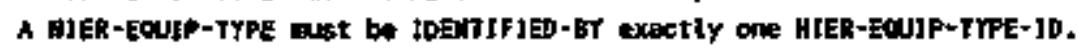

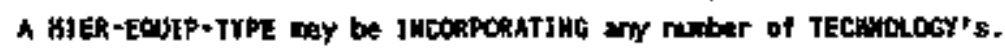

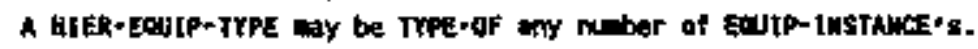

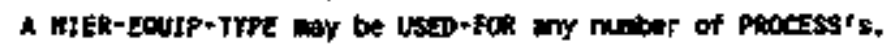

A G]ER-EOULP-TYPE-10 is a LABEL TYPE wFth representation character 6.

A A]ER-EOUIP-TYPE-ID niny be IOENTJFIER-FOR at wast one HIER-EOUIP-TYPE. 
Elerientary Senterke.

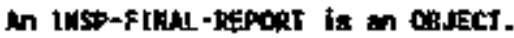

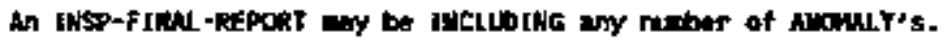

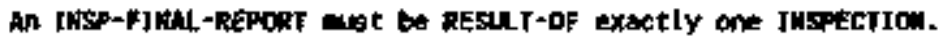

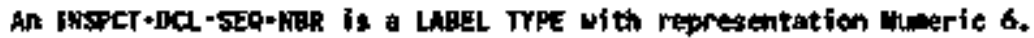

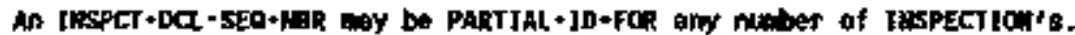

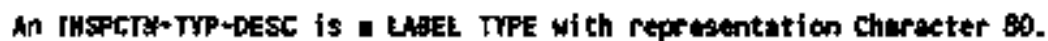
An INSPCTH-TYP-DESC may be DESCR IE]MG any number of JHSPECTTON's.

An JMSPECT-DECLARE-JD is a LABEL TYPE with repesentotion Character 6.

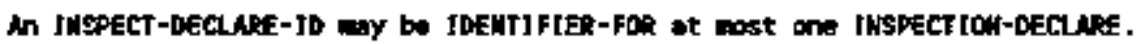

in IHSPECT-TYPE-DESE is a LAEEL TrPE wi th representation Charecter 00. in IHSPECT-THPE-OESt to be DESCRLPTIOH-FOR an nubar of JWSPECTIOU-TYPE's.

An INSPECTNALE-AREh is an OBJaCT.

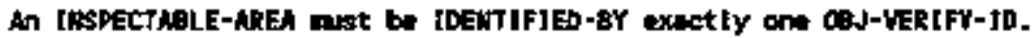
An inSPECTABLE-AREA my be LOCAIJON-0F any nobr of IhSPECTABLE-CRG's. An JNSPECTHELE-NREA woy be REVIEUED-BY any nuber of InSPECTICo's.

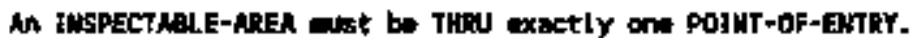

An JMSPECTARAE-ORG IS a OBJECT.

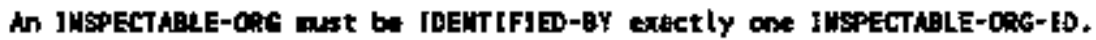
An IMSPECTABLE-ORG must be LOCAFED-IN one or more INSPECTABLE-AREA' $\$$. in IMSPECTAELE-OAG wust be LOCATED-SITE one or bore SITE's.

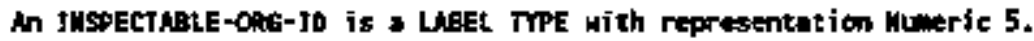

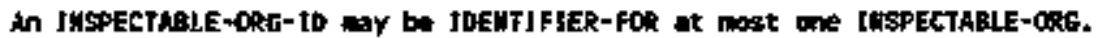


Elapontary santence.

An JHSPECIIOH is en OB.ECT.

An JWSPECTJOM must be ALLOWED-gY extectly one TREATY.

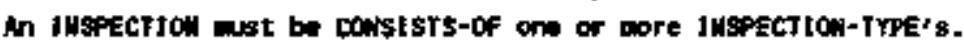

in iNSPECTION mast be DOMERep-ar exactly one INSPECTICH-DECLARE.

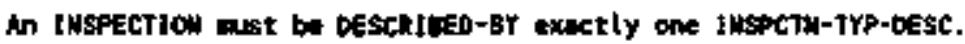

An [NSPECTION aust be ENDGD-d exBctly ore DATE.

in INSPECTJow anst be EScokita-BY exectly one ESCORT-TEAN.

An IMSPECTIOW mst be FOR exactly one JUSPECTRBLE-NREA.

An tusPection ass be IDEUTIFIED-BY oxactly one thSPECTIOA-to.

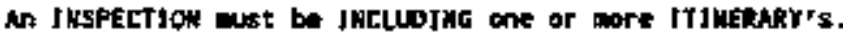

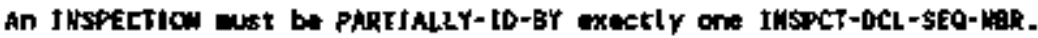

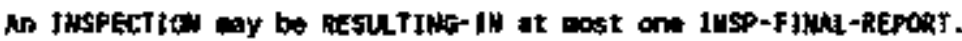

An inSPECIION and be souRce-FOn any number of SAMPLE's.

in InSPECTION nust be STARTED-On exactly ane DATE.

Every IMspectitu

is associated iniquety with one combinet ion of

an INSPECTION DECLAME COVERIMG the JMSPECTION

ond an JWSPCT DCL SEP MER PARTIAt ID FOR the EKSPECTION.

An [HSPECT]OW-DECLARE IS OS OBJECT.

in INSPECTION-DECLNR mst be CONLRED-eY Exactly ant TREATY.

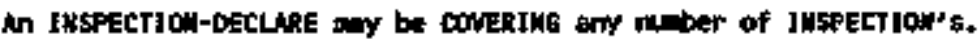
An [WSPECT]ON-OECLAR wast be OECLARED+BY exactly one COANTRY. An INSPECTJOW-DECLARE mat be DECLARED-ON EXACTlY GRe COUNTRY. An IRSPECTIOW-DECLARE aust be GECLARED-ON EXactiY one DATE.

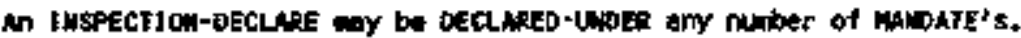

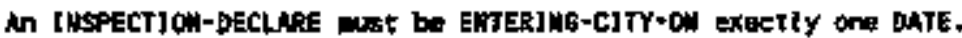

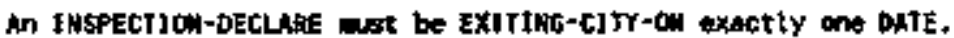

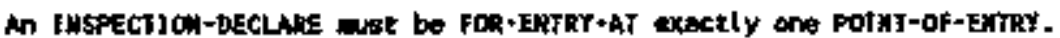

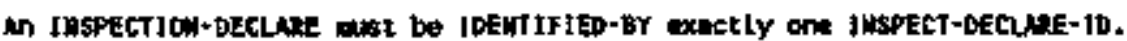

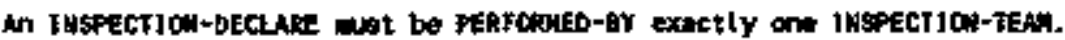

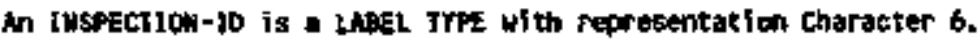

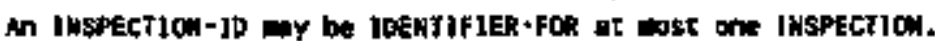

M IUSOECTHON+TEAH is An OBNECT.

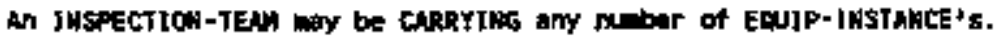

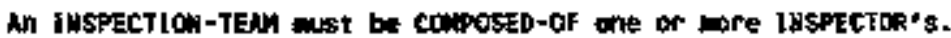

An IMSPECTIOGi-TEAM must be HAS-CH]EF exactly one JUSSECTOR.

An JUSPECTION-YEAM most be JDENTJFED-BY exactly one IUSPECTJON-TENA- ID.

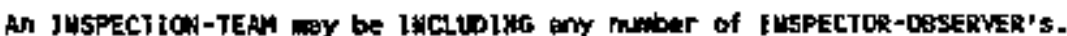
An JUSPECTICA-TEAM WISt be PERFoFMIMG one or DOr INSPECTJOA-DECLARE's. 
Etement ary Senteqnce.

An IUSPECTICR- TEAm-10 to a LaBEL TYPE tif th representation Oharater 6.

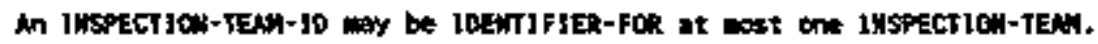

An JUSPECTION-TYPE is \&n OQNECT.

An IMSPECT IOW-THFE WOY be NLLOEO-BY any maber of TREATY-CLAUSE's.

An INSPECT ION-THPE WY be CHECKED-FOR ATY nuber of TAEATY-LIMIT'S.

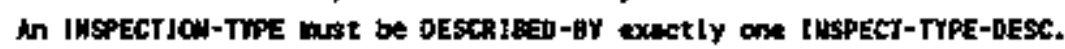

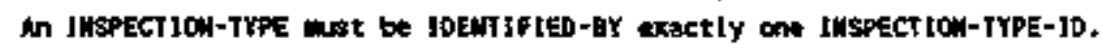

An IMSPECTION-TYRE try be USED-FOR any nuber of INSPECTION"s.

An IMSPECT1OH-TYPE-TD is D LABEL TYPE with representation Muperic 5.

An JUSPECT1OW-TYPE-HD Wy be JOERTIFIER-FOR at aOst one IUSPECTICW-TYPE.

in IUSPECTOR is an QQJECT.

in Juspectoc is stwoss a kind of PEusow.

An INSPECTOR ary be CHEF-FOR any nemiber of IMSPECTIOW-TEN's.

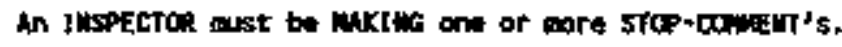

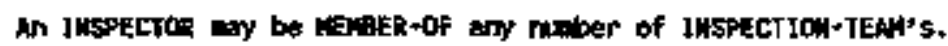

An IMSPECTOR ay be DEOLESTIN any number of SAMPLE'B.

An IMSPECTRR way be REOUESTCR-FOR any muber of MNALYSIS's.

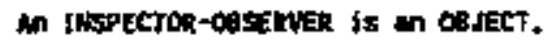

in thspecrok-GasaRVER is stways a kind of PERSON.

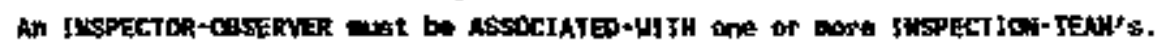

An ITEH-DESC is a LABEL THDE with representation tharacter 50 .

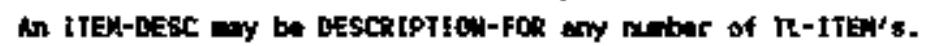

An llimgtakt is in QDJECT.

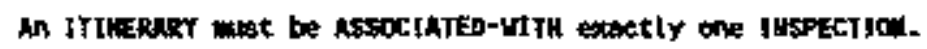

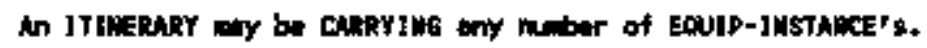

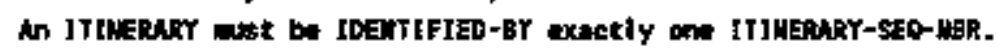

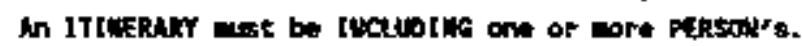

An ITIMERARY nest be STCPS-AT one or wore sTop's.

Every trinterary

is essocitated uniquely with one combination of

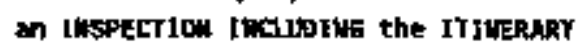


Dote: $5 / 2 / 93$

Hodel Hane ; os $\$ 51$
Hodel buscription in current largegept.

version : $2.40 \mathrm{a}$

El eaventary sentente.

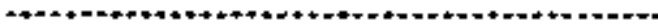

and on JTIMERARY SEO MBR JOENTIFIER FOR the ITHMERARY.

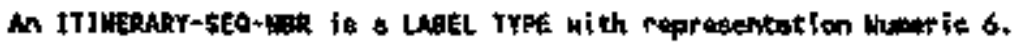

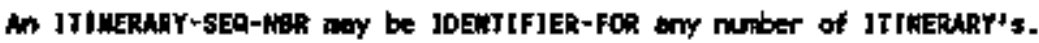

A LD-UNIT is a LUEEL TYPE with representstion Chacecter B.

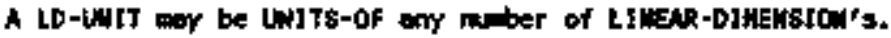

A tD-VhLUE is a LABEL TYPE with representation Numerite 7.

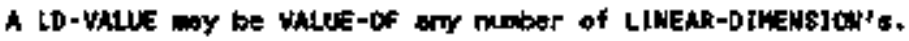

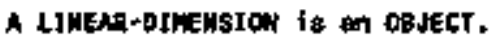

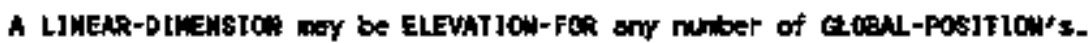

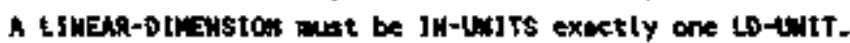

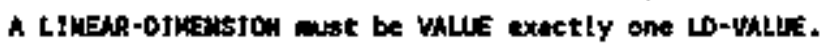

Every LJWEAR DIVENSION

Is assoctieted uniqualy with on combiention of

a ID Gitt LAtis of the CIWEAR DIHERston

and 9 LD vaUE VALUE OF the tIREAR DineNsion.

A LOCATION it on OAdECT.

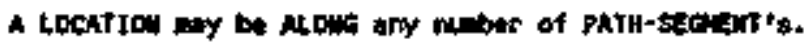

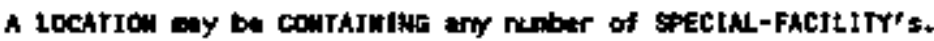

A Lochition ney be fok ary number of serpte's.

h tochtion noy be fok on rumber of stop's.

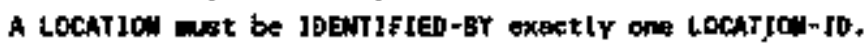

A LOCATION nay be IhCLInep-If at wet and EuItbint.

A LOCATION noy be LOCATION-OF ony mubet of Aletrsis's.

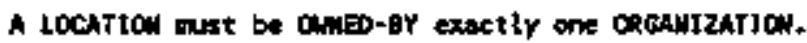

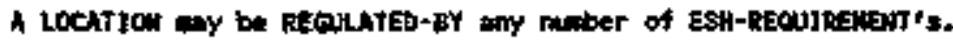

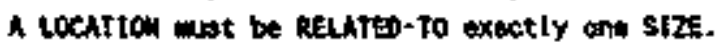

AOCATION mey be WITH any nuber of EscoRI'A.

A LDCATIOH-10 is a LABEL TYPE with reprobentotion charater 6.

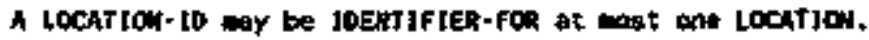


Elewentary Senterce.

A wurate is in gaject.

A wathe west be fot exactly ane laspection-DECLNe.

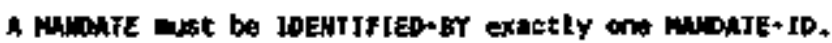

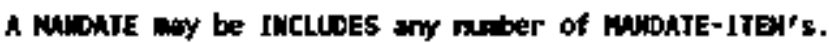

A WHATE+1D is a LABEL JYPE with representation Muserie 5.

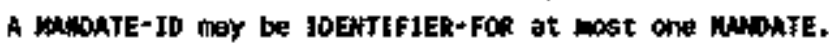

A WHDATE-ITEM is m OBSECF.

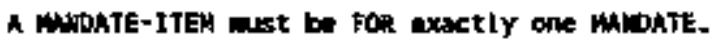

a MAMATE-ITEH mst be PARTIALLY-ID-BY exactlY one MADATE-SED-MBR.

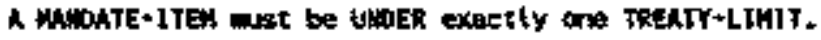

Every NWhate tTen

is associnterd uniquly with on cowbination of

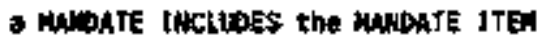

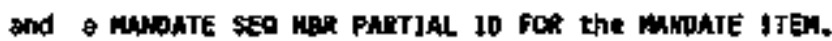

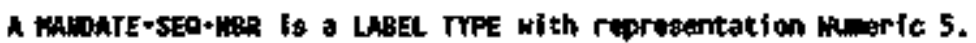

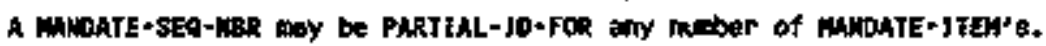

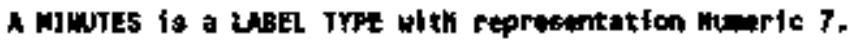

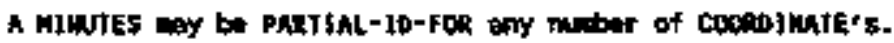

A werth-tOOE is a LABEL TYPE with representation thasucter 2.

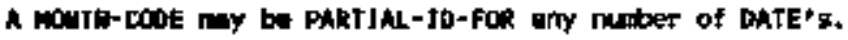

A Wute is a LABEL ITPE with representation character 50.

h Whute ary be FOA any nuber of persow's.

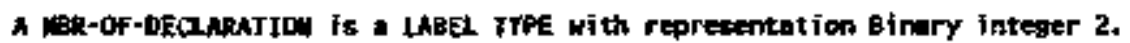

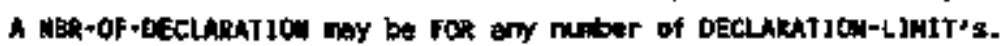


Elenentsry sentente.

A AESH-OOOE is a LABEL TYPE with representetion Character 1.

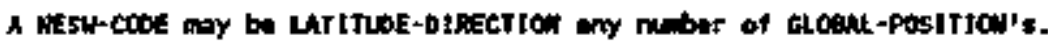

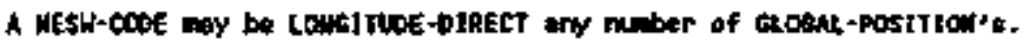

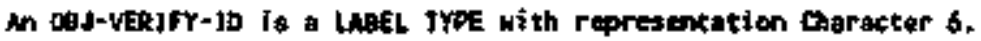

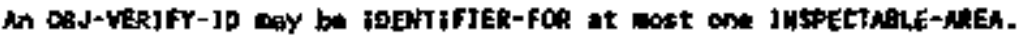

An conarizhtor is on oiflect.

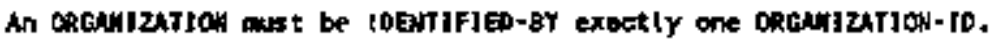

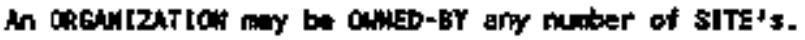

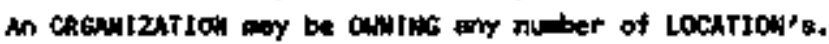

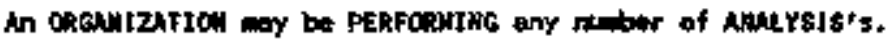

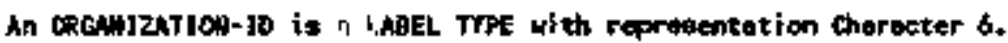

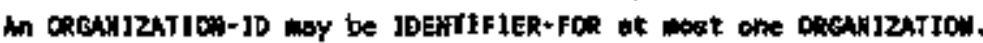

A PASSPORT-HBR is a LABEL TVPE with repreoentetion chorecter 6. A PASSPORT-HER boy be GiVEk-TO any nimber of PERSOA's.

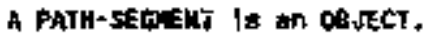

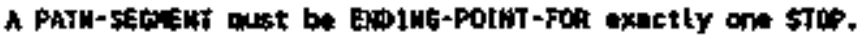

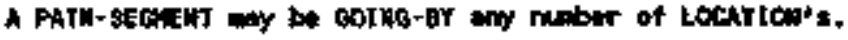

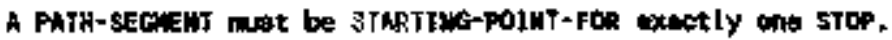
EWETY PATH SECAENT

is bssociated uniquely $y$ ith one combintion of - STOP stARTS AT the PATH StEHiWt

and STOP EKDS AT the ?ATH SEGTEM.

A PERICD-OF-T1WE is a LAPEL THPE with representation Muneric 6.

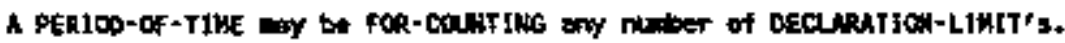

A PERSON is an CBJEct.

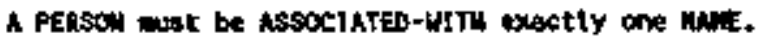


Date: $5 / 2 / 93$

Hodel Wase ; DSt51
Hodal Desertiption its current languge.

version : 2.400

Elewentary Sentente.

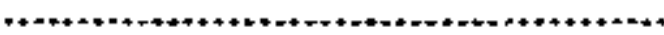

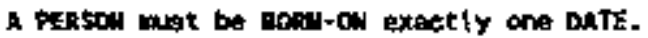

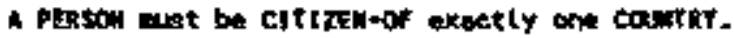

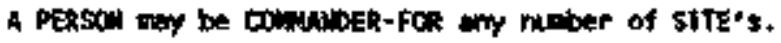

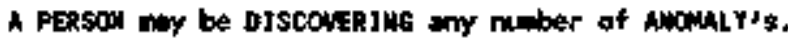

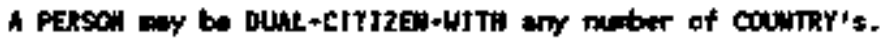

a PERSOM met be GJVEN exactly one PASSPORT-MBR.

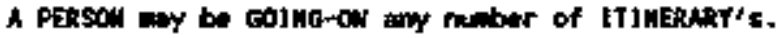

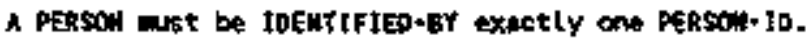

h PERSOW+10 is a Latel TYPE with representetion thapacter 6 , A PERSOW+ID ay be IDEUTIFIER+FCR at aost one PERSON.

A POINT-OF+ENTRY is an adVTI.

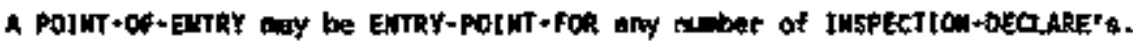

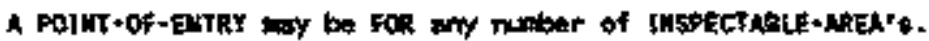

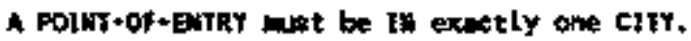

A POIMT-OF-ENTR' met in exactly one colmter.

A POIMT-OF-ENTRY wy be SPECIFIED-BY ary mimer of TREATY's,

A PROCESS IO * DONECT.

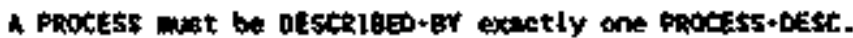

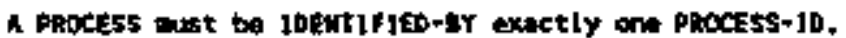

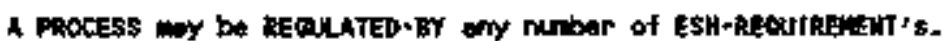

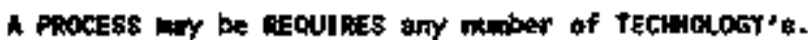

A PROCESS moy bo USJWG any nember of HIER-EQUIP-TYPE'S.

A PROCESS-DESC is a LAREL TYPE with representution Choracter $\$ 0$.

A phocess-Dest way be besenteting any nuber of paocess's.

1 Pkotess-to is we Let TreE with repreatentation character 6 .

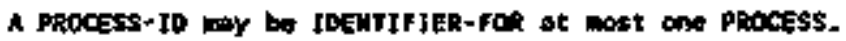

A. REGLOA is an OBJECT.

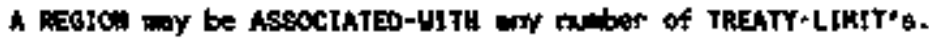

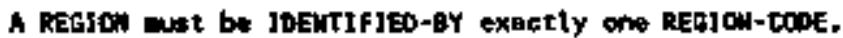

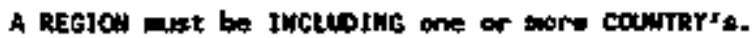

A REtion west be Krown-sy exectiy one REGlaw-WHE. 
Elewartary Sertemce.

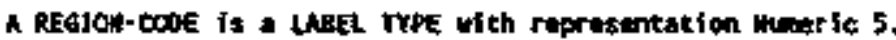

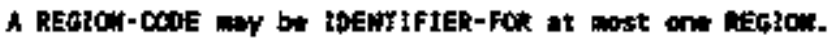

A RESICor-WhE is a IABEL TrPE with reyresentation theractor $B 0$,

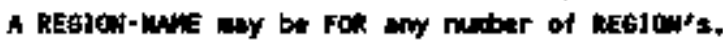

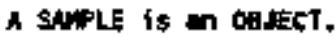

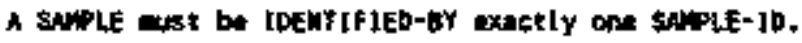

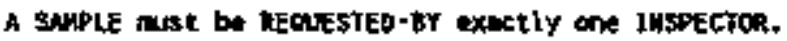

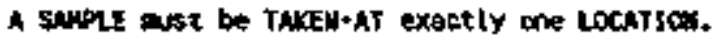

A SUUPLE and be THEN-BY exostly one ESCORT.

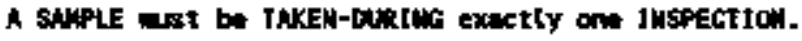

A SAMPLE mest be TAKEN-OW exactly one DATE.

A SAMPLE wry be FESTED-EY any nemer of NWLYSIs's.

A SATPLE- to is : LAGEL TYPE with representotion meric 5.

A SUPLE-Lo wy be 1DENT JFIER-FCR at nost one SAMPLE.

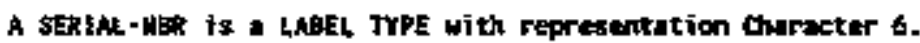

A SERIAL-WBR nEY be PARTJAL-10-FOR any nuber of ECHF-JMSTMNCE'S.

A SITE is on DeNECT.

h SITE is atwors a kind of IHSPECTABLE-AREA.

A SITE nst be ASSOCJATED-WITH Exactly one SETE-TYPE.

A SITE mast be ASSOCJATEb-HITH Etactly one TREATY-SITE-DEFC.

AITE ay be ASSOCIATED-WITH any Muber of TWEATY-SITE-OSRM'\$.

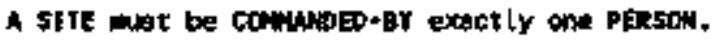

A SITE nust be COVERED-EY one or wore TREATY's.

A SITE wat be DESCRIBED-ar exactly one SITE-0Esc.

A SITE ast be JDENTJfIED-BS exactly one SITE-ID.

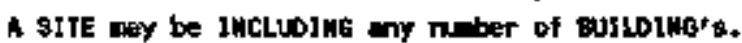

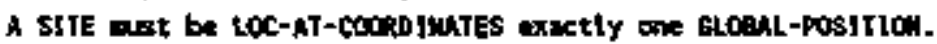

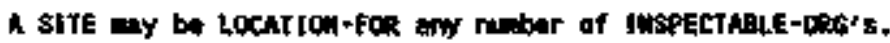

A StIE wast be ondek+of exactly one oncaljzatlog.

A SIIE mer be PeRFonilno any number of Functon's.

A SITE my be LutoR any mubet of TREATY-LIAJT's. 
Elenentery sentenct.

A 51 ye-bESC is a LABEL FTPE with representation character 30 .

A SJTE-besc way be DESCRIPIJOW-FOR any maber of 5ITEfa.

A S!TE-ID is a LABEt FWFE with reprosinkation character 6 .

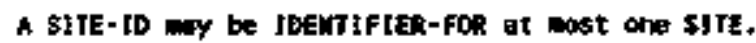

A SITE-TTPE is en CQJECT.

A SITE-TYPE most be DESCRLeE -BY exactly ane sI TE-TYPE-DESt.

A SITE-TTPE my be fot any nuber of SITE'b.

A SITE-TYPE nust be 1DEWTtFIE-Br exactly one SITE-TYPE-JD.

A SITE-TKPE noy be UNDE any mubar of TREATY's.

A SIJE-TYPE DEY be UADER any nubor of TREATY-LIAIT'\$.

A SIIE-TYPE-DESC Is a LASel THPE vith representstion character 80.

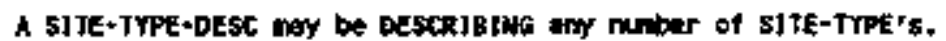

A SIJE+TYPE+ID is o LABEL TYPE With representation MUNeric 5.

A SITE-TYPE+3D WI be IOENIIF]ER-FOR at wost on SITE-TTPE.

A \$17 Is a LABE IYPE with representation moserle 6.

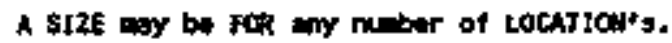

A SPEC-FACILIJY-ID $3 s$ a LABEL ITPE with representation Chorocter 6.

A SPAC-FMCILITY-i Day be IOENTIF1ER-FOR or nost one SPECIAL-FACICITY.

A SPECIAL-FACIEJTY is en OQJECT.

A SPECIAL-FACILJTY ast be JDENTJFIGp-ar exactly on SFEC-FMcILETY-Ib.

A SPECLAL-FACILJTY wa be LOCATED-AT any nerber of LOCATICa's. 
Eltenențary Sentence.

A SPECIFIC-TL-ITEM is an OBJECT.

A SPECJFIC-TL-17gd mest be conpostic exectly one TL-ITEh.

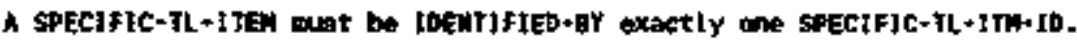

A SPECIFIC-TL-ITH-ID is - LAEEL TYPE with representstion moric 5.

A SPECIFIC-TL-ITN-JD moy be JDENTIFIER-FOR st most one sPEC]FIC-TL-]Tak.

A STOP is an OBJECT.

A STOP must be AT exactly one LOCATIOA:

A STOP noy be EADS-AT any nuber of PAIH-SECNENT's.

A STOP anst be ESCORTED-BY ane or nore ESCORT's.

A STOP mast be IDENTEFIED-BY exactly one 5FOP-SEO-WOR.

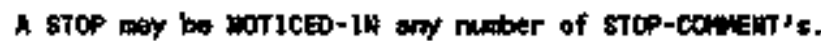

A STOP nust be OCCLRRED-AT exactly one ilwe.

A STop asy be STARTS-AT any nuber of PATH-SEGLENT's.

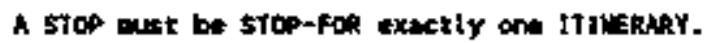

Every STOP

is associsted uniquely with one combination of

an ITSBERARY STOPs it the STOP

and a STOP saO Whe SOEnTtF1ER FOR the STOP.

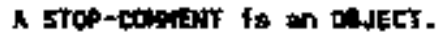

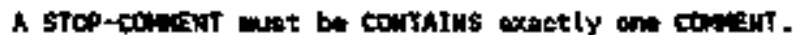

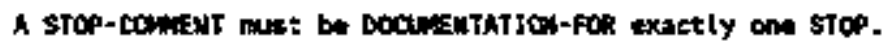

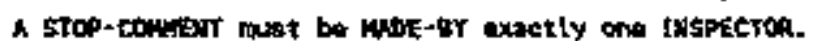

A STOP-COAnEN way be OWERHEkSD-BY any nuber of ESCORT's.

Every STop COMnENT

is associsted uniquely with one ecabinstion of

- Comizar foa the szep conient

and - STOP WOTtces IN the STOP COMwent

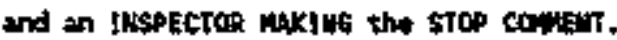

A stop-SEQ-MaR is a LABEL TyPe with representetion weric 6 .

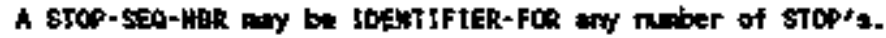

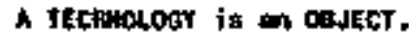

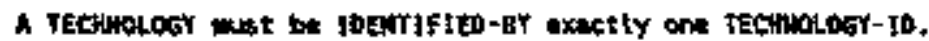

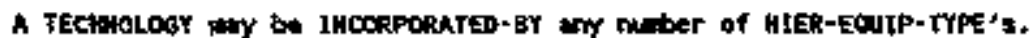

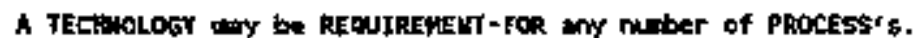


El enentary Sentence.

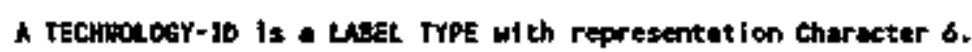

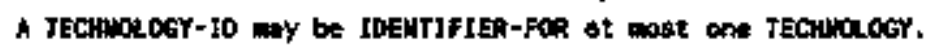

A TIKE is an DeJECT.

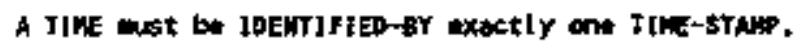

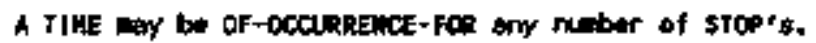

A TJEE-STHF is a LABEL TYPE with Fapresentation Mumeric 6.

A THME-STAN may be tbENTIfIER-FOR at most one T1ME.

A TL-EOUJPWENt is an GeJect.

a T1-EoufPitant is alwas a $\mathrm{k}$ ind of TL-ITes.

A TL-2TEW is an OBJECT.

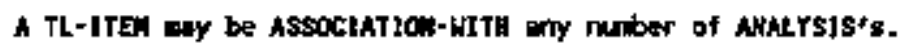

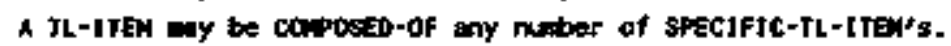

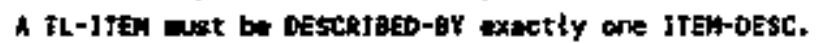

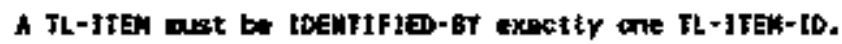

A IL-JIEN asy be JTgA-fot any rumber of TREATT-1IHIJ's.

A TL-17EN-10 is a LaEel TYPe with represtentation muric 5.

A TL-ITEA-ID nay be IbENTJfIER-FOR at nost one TL-JTEN.

A TL-Minte lon is an CONECT.

$A$ TL-WUnzTIO is ol ways a kind of TL-JTEN.

A TL-PkOCESS is an CBJECT.

AL-PROCESS is alwys a kind of TL-ITEM.

A TREATY Is an OBJELT. 
Eleantary Sentence.

A TRERTY mast bo COAS15TIHG-Of are or wore TREATY-CLAUSE's.

$A$ TREATY wy be CONERIUG any muter of COUNTRY-SITE's.

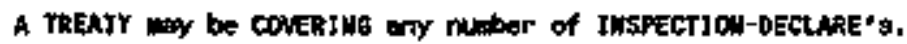

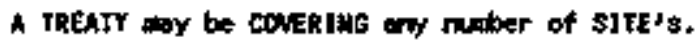

A TREATY must be JOEHJIF1ED-BY exactly one TREATY-1D.

A TREATT maY be RELATED-TO any nuber of SITE-TYPE'S.

A TRERTY noy be SPEClffIEs any neter of POINT-OF-EWTRYrs.

A TREATY moy be SPECIFYTHS-AM Bny nuber of INSPECTION's.

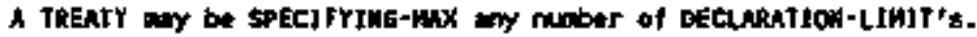

A TREATY nay be VITH any nuber of TREATY-SITE-bGkH's.

A TRERTY-CLAUSE is an Dentet.

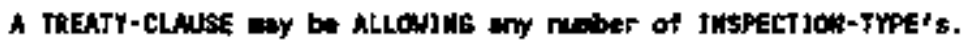

A TREATY-CLAUSE mot be CONTAINITG exactly on TREATY-CLNASE-TEXT.

A TREATY-CLAUSE mast be JMELLDED-JW axaczly one TREATY.

A IREATY-CLUUSE Wast be PARTJALLY-ID-BY EXactlY One TREATY-tLAUSE-ID.

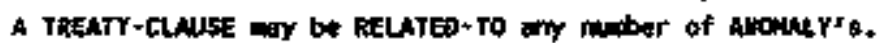

A TREATY-CLAUSE Day be SPECIFYIU6 any maber of TREATY-LJKIT'S.

EVETY TREATY CLAUSE

is associnted uniquily ulth one conbination of

a TREATY CONSISTIM of the TREATY CLNSE

and I TREATY CLUUSE ID PARTIAL IO FOK the TREATY CLUUSE.

A TREATY-CLAUSE-JD is a LABE TYPE with representation Binzry integer 5.

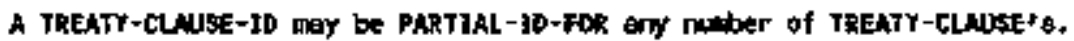

A TREATY-CLAWEE-TEXT is a LAEL TYPE with PEP waentation char acter 80 .

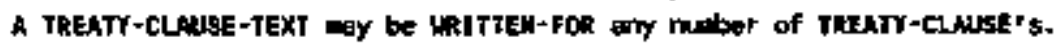

A TREATY-ID is a LABEL TYFE with representation Character 6.

A TREATY-jb eny be IDERT TFjek-FD at most one JREATY.

A TREATY-LHWI IS An OBJECT.

A TREATY LEAIT MV be CHECKED-BY any mer of IASPECTIOW-TYPE's.

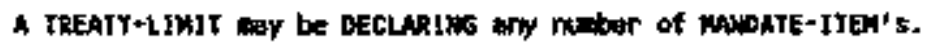

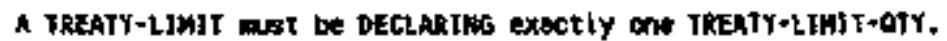

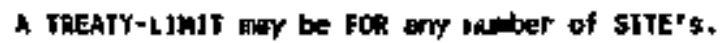

A TREATY-LIWIT ESY be FoR at nost one SIJE-TYPE.

A JREAIY-LIHIT must be fon exactily one Tt+ITEM.

A IREATY-LIMIT MOY be FOR-CAMER at most one CDUHTRY. 
Etementary sentence.

A TREATY-LENIT noy be th at wot one COUNTRY.

A TREKTY-LINIT way be IN at moat one REG]ow.

A TREATY-LIMIT Whet be SPECIFIED-JW exactly one TRERTY-CLNUSE.

EverY TREATY LINIT

is associated uniquely vith one combination of

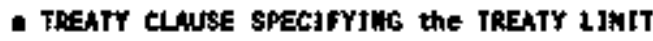

and a TL ITEM JTEN FOR the TREATY LJkIT.

A TREATY-LINIT-OTY IS a LABEL TYPE wf th representestion Muneric 3.

A TREATT-LJAIT-OTY nOY be DECLARED-GWEER any miber of TREATY-LJHIT's.

A TREATH-STJE-DEsc is an DejEct.

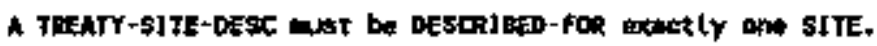

A TREATY-SITE-DESC DHSt be REPRESENTED-1II one or wore DOCINENT's.

A TREATY-SITE-DER is on GBJECT.

A TREATY-SITE-DERA Nast bo FOR wact:Y on TREATY.

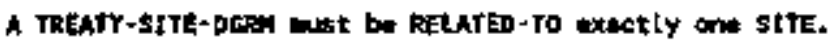

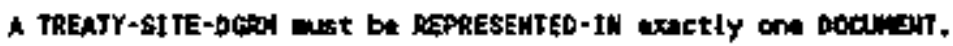
Evary JKSHEY SJTE DCRH

is associated unieuely with one conbination of

- JPEATY UITH the JREATY SIJE DEBM

and a \$ITE ASSOCFATED WITE the TREATY SITE DEMA.

a Verstou is a LAgEL TTPE with representation Charecter 5.

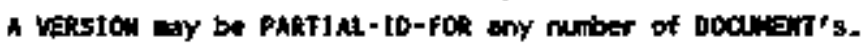

A Yenk-tone is a LABEL TYPE wi th representation Charecter $Z$,

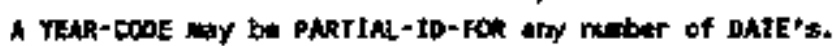




\section{DISTRIBUTION:}

1 MS 0160 Virgil Dugan, 4500

10188 Chuck Meyers, 4523

10459 John Taylor, 5335

10473 Sharon Deland, 5391

$10661 \quad$ Gary Rivord, 4012

$10863 \quad$ Paul Flores, 14307

$1 \quad 1138 \quad$ Lanty Claussen, 6533

$1 \quad 1373 \quad$ Arian Pregenzer, 5341

$11 \quad 1378$ Olin Bray, 4524

11378 Shanna Narath, 4524

I 9018 Central Technical Files, 8940-2

50899 Technical Library, 4414

20619 Review \& Approval Desk, 12690

For DOE/OSTI 